\title{
A LONG-SNOUTED LATE EIFELIAN ARTHRODIRE FROM ARAGÓN (SPAIN)
}

\author{
Elga MARK-KURIK' ${ }^{\prime}$ and Peter CARLS ${ }^{2}$ \\ ' Institute of Geology at Tallinn TechnicalUniversity, Estonia Avenue 7, EE \\ 10143 Tallinn, Estonia. E-mail: kurik@gi.ee \\ ?Institut für Geowissenschaften, Technische Universität Braunschweig, \\ Pockels-Str. 3, D 38106 Braunschweig, Germany.
}

\begin{abstract}
Mark-Kurik, E. and Carls, P. 2002. A long-snouted late Eifelian arthrodire from Aragón, Spain. [Un artródiro con rostro alargado en el Eifeliense tardío de Aragón, España.] Revista Española de Paleontología, 17(1), 117135. ISSN 0213-6937.
\end{abstract}

\begin{abstract}
Carolowilhelmina geognostica Carls, 1995 is a large arthrodire (Placodermi) from the Tortodus kockelianus Conodont Zone, late Eifelian, in the Eastern Iberian Cordillera in southern Aragón. The somewhat incomplete but articulated skull is preserved, showing a long tubular rostral plate, very small postnasal plates, low toothless inferognathals, and a small, slender and flat parasphenoid. Supraorbital and central sensory lines meet their antimeres at the midline of the skull, forming a straight double line. Lines along the ventral surface of the rostral plate probably belong to the suborbital branches of the infraorbital sensory lines. The combination of characters of Carolowilhelmina points to a separate taxonomic position of suprageneric rank. The specimen is from a pumilio bed of the unit $\mathrm{E}$ of the Moyuela Formation. It lived in pelagic environment with floats of algae bearing epiplankton.
\end{abstract}

Keywords: Arthrodira, long rostrum, pelagic environment, Middle Devonian, southern Aragón, Spain.

\section{RESUMEN}

Carolowilhelmina geognostica Carls, 1995 es un artródiro (Placodermi) grande de la Zona de conodontos de Tortodus kockelianus, Eifeliense tardío, en la Cordillera Ibérica Oriental, sur de Aragón. Se ha conservado un cráneo algo incompleto, pero articulado, con una placa rostral tubular alargada, placas postnasales muy pequeñas, placas inferognatales bajas y sin dentición, y un pequeño, delgado y plano parasfenoide. Las líneas sensoriales supraorbital y central se juntan con sus antímeros en la línea de simetría, formando una doble línea recta. Las líneas en la superficie ventral de la placa rostral son probablemente extensiones de las ramas suborbitales de las líneas sensoriales infraorbitales. La combinación de caracteres de Carolowilhelmina sugiere una posición taxonómica separada a nivel supragenérico. El ejemplar se halló en un banco pumilio de la unidad E de la Fm. Moyuela, en facies pelágica; vivía bajo algas flotantes con abundante epiplancton.

Palabras clave: Arthrodira, rostro alargado, ambiente pelágico, Devónico Medio, sur de Aragón, España.

\section{INTRODUCTION}

The first Devonian fish remain to be described from the Eastern Iberian Cordillera was the head of the fairly large onychodontiform sarcopterygian Grossius aragonensis Schultze, 1973. That specimen stems from the same horizon as the present Carolowilhelmina geognostica, but from a nearby locality. The first parts of this arthrodire were recognized on a field trip by Otto $\mathrm{H}$. Walliser in April 1971 after the following events. Measuring the section of the Moyuela Fm. near Molino Bajo (Figs. 1, 2)
Carls had broken a limestone nodule for a conodont sample out of the wet slope but had rejected it, at dimming evening light, as it appeared to be too impure for acid treatment. Next morning, at bright sun and after the creek below the section had washed the fragments clean, these were recognized by Walliser to contain bones. The provenance of the fragments could not be detected, probably because a portion of the wet slope had slid down and covered it. However, the search for fish remains was continued at other outcrops of the same guide level and resulted in the discovery of Grossius. At 


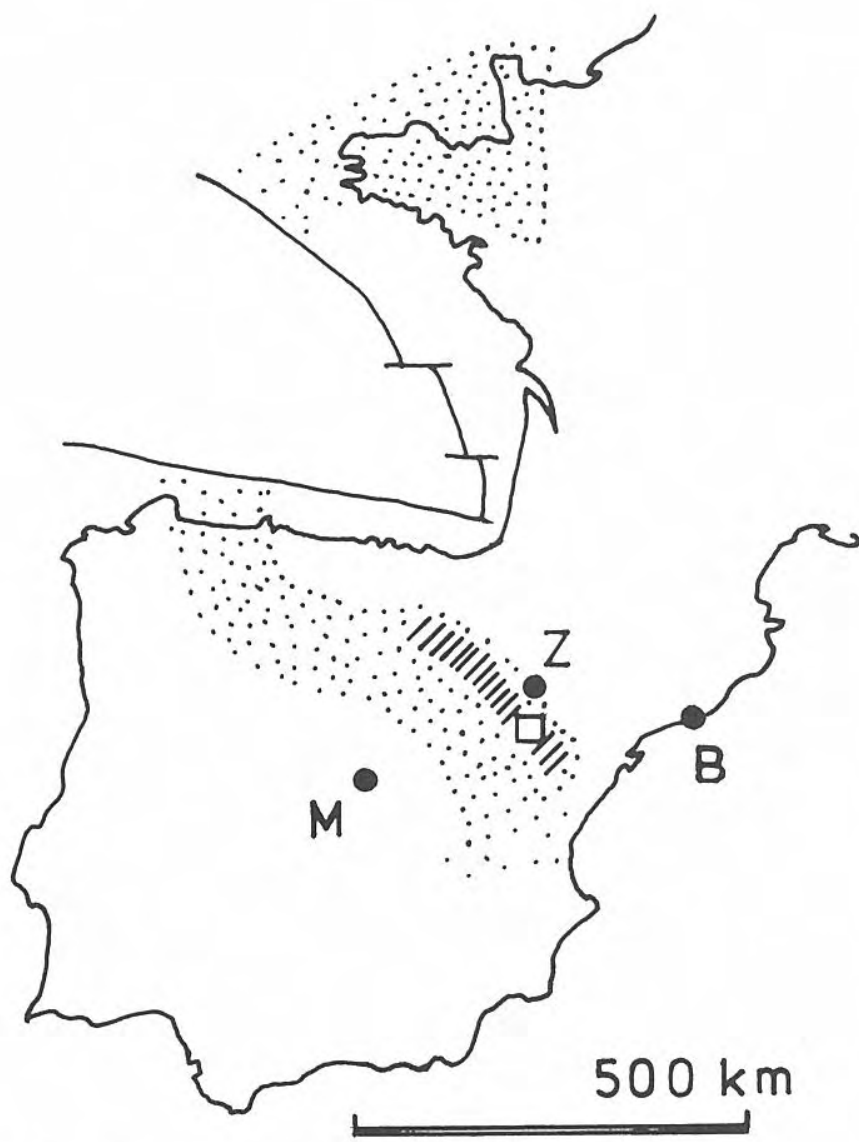

Figure 1. Geographical location of the type region (square) on the Iberian Peninsula. $\mathrm{M}=$ Madrid, $\mathrm{B}=$ Barcelona, $\mathrm{Z}=$ Zaragoza. Hatched area $=$ Eastern Iberian Chain. Stippled area $=$ reconstructed Ibero-Armorican Trough in northern Spain and middle plus northern Armorican Massif.

Göttingen, Hans-Peter Schultze, besides describing the latter onychodontiform, recognized the fragments to be placoderm remains, but he did not proceed further. In 1986, the Molino Bajo section happened to be well exposed, as the creek had removed the talus. Now, an oblique section through the rostrum was visible (the repaired fracture at half length of the rostrum of Carolowilhelmina). The enclosing block was taken out, and its preparation through Carls since 1992 resulted in most of the present fossil. In 1993, Carls as a non-expert in fossil fishes, showed Schultze a drawing of the skull and asked for advice as to classification and further procedure, which was kindly given. Schultze remembered that he had already seen the oval oblique section of a tubular bone in the fragmentary sample of 1971. These fragments were produced from his collection in Göttingen and they turned out to be the middle portion of the rostrum of the same specimen. The frontmost part was destroyed through erosion before 1971 .

Preparation of the skull was mainly achieved by etching in formic acid (about $5 \%$ ) and by mechanically removing shales and the silicate framework of the marl and impure limestone. Many times, in the measure

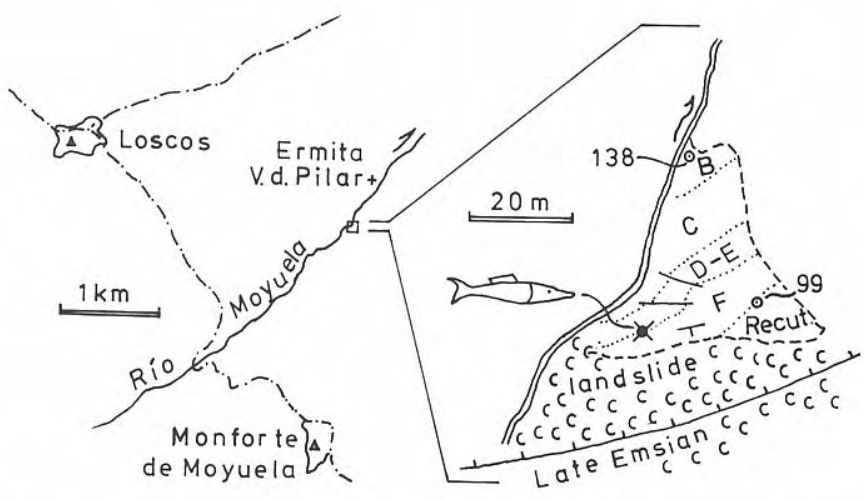

Figure 2. Type area and sketch map of outcrop at the type locality above Moyuela Creek. 138, $99=$ numbers of basal (138) and top (99) beds of section Molino Bajo. B - F = units of Moyuela Formation.

carbonate was removed, the acid bath was interrupted, the resulting formiate was washed out in repeated water baths, the specimen was dried, and the porous and rather brittle bone was strengthened through impregnation with cellulose lacquer. Thereafter, softened silicate remainders were removed by means of a needle or soft brushes. After the acid treatment of larger areas was essentially finished, endangered thin and fractured bones were also impregnated with thinly fluid but immediately hardening cyanacrylate glue, which strengthens the bones enough to be cleaned with a rotating brass brush.

Further acid treatment is not recommended, because the organic materials applied as well as the epoxide resin that forms the socle and fills some fissures, would soak the organic acids like solvents and would thus cause interior movements and breakage within the bones.

The nomenclatural status of the taxon described here requires the following comments. Without aiming at nomenclatural validity, Carls (1995) presented and illustrated the skull (which is holotype by monotypy) in a popular article on occasion of an anniversary of his university. This was done in a regularly published print medium of the university, which generally, though not exclusively, has the "purpose of providing a permanent scientific record" (Article 8al of the International Code of Zoological Nomenclature of 1985). The combination "Carolowilhelmina geognostica nova species" was introduced therein; but this was done with reference to the future and remarking that the nomenclatural validity would be established later, which remark was meant as a disclaimer. However, this disclaimer did not satisfy Article $8 b$ of the Code, which required that the issue "for permanent scientific record" be disclaimed. P.C. regrets that, due to the first publication in 1995, he can be considered as author of the name, although that was not intended.

A short characterization of the fish and comparison with the other long-snouted arthrodires was presented as a poster at the meeting on the early vertebrate evolution in 1999 in London (Mark-Kurik and Carls, 1999). The specimen is preserved in the collections of the 


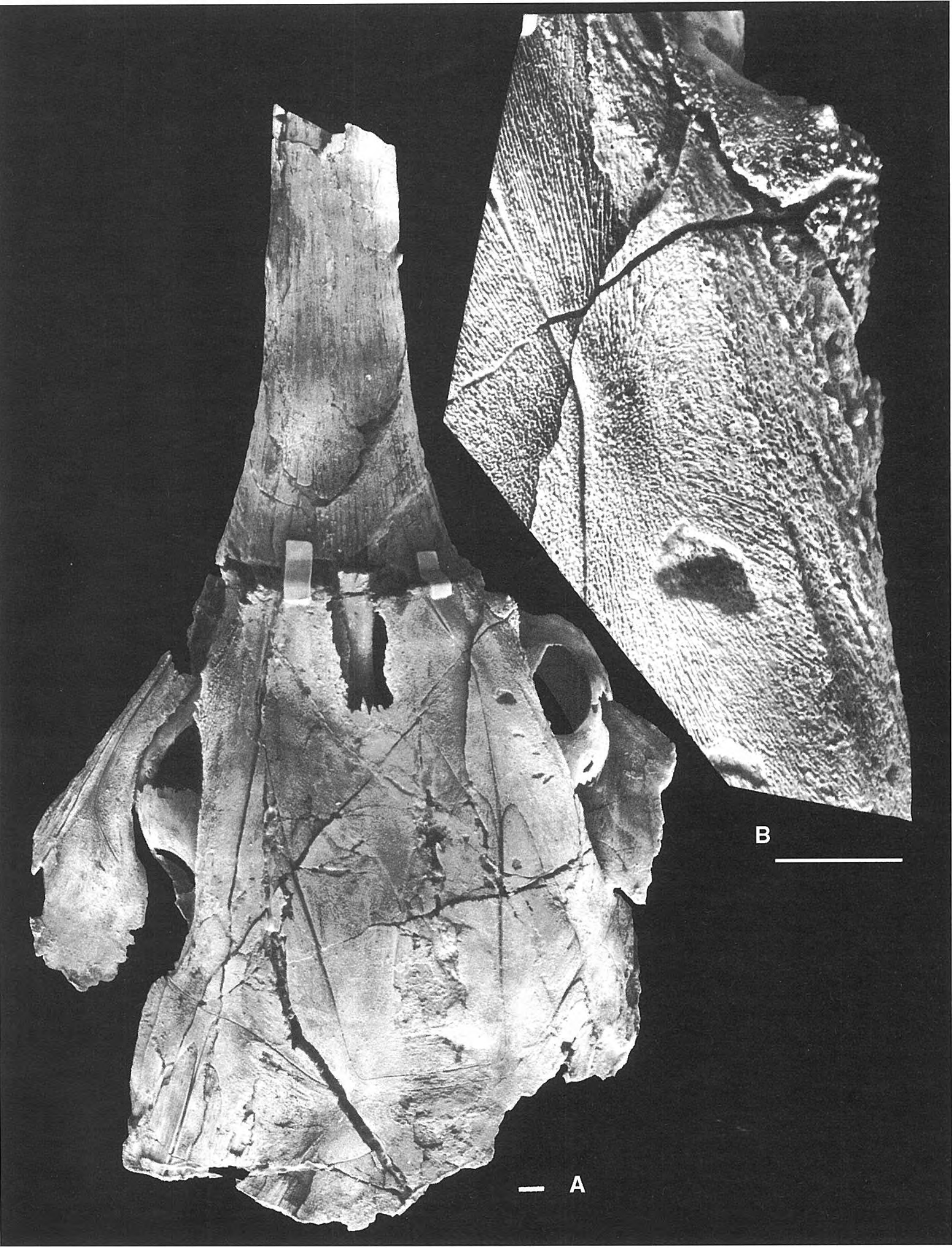

Figure 3. Carolowilhelmina geognostica Carls, 1995. Skull, Holotype MPZ 95/174. a. Dorsal view. b. Detail of the anterolateral portion of the right preorbital and the right postnasal plates. Scale bars $=1 \mathrm{~cm}$. 
Palaeontological Museum of the University of Zaragoza (Museo Paleontológico de la Universidad de Zaragoza) under the catalogue number MPZ 95/174.

\section{Abbreviations}

a.pr $=$ antorbital dermal process; $\mathrm{bl}=$ blade; $\mathrm{C}=$ central plate $; \mathrm{cr} . \mathrm{m}=$ central median crest $;$ csc = central sensory line; dex = right; e.op = eye opening; $\mathrm{fd}=$ functional division; $\mathrm{gr}$ = groove; gr.Mm = groove for mentomeckelian bone; $\mathrm{IG}=$ inferognathal; IN = internasal plate; ioc.ot, ioc.pt, ioc.sb = otic, postorbital and suborbital branches of infraorbital sensory line; $\mathrm{kn}$ = spongy "knob"; l.s = lateral spine; $\mathrm{M}=$ marginal plate; M.oa = overlap area for marginal plate; $\mathrm{m} . \mathrm{pr}$ = median process $; \mathrm{nn}=$ nasal notch $;$ oa $?$ = overlap area?; oc = opercular cartilage orb $=$ orbital opening; $\mathrm{P}=$ pineal plate; pa.phyp = pre-hypophysial part of parasphenoid; $\mathrm{PN}=$ postnasal plate; PN.oa = overlap area for postnasal plate; $\mathrm{PrO}=$ preorbital plate PSO $=$ postsuborbital plate; Psp = parasphenoid $; \mathrm{PtO}=$ postorbital plate $; \mathrm{R}=$ rostral plate; $\mathrm{Scl}_{1-4}=$ anterior, dorsal, posterior and ventral sclerotic plates; $\mathrm{Scl}_{4}$. oa = overlap area for ventral sclerotic plate; sin $=$ left $; \mathrm{SM}=$ submarginal plate; $\mathrm{SO}=$ suborbital plate; $\mathrm{SO} . \mathrm{oa}$ = overlap area for suborbital plate; soc = supraorbital sensory line; suo.v = supraorbital vault; th = thickening; v.th $=$ ventral thickening.

\section{SYSTEMATIC PALEONTOLOGY}

\author{
CLASS PLACODERMI McCoy, 1848 \\ ORDER ARTHRODIRA Woodward, 1891 \\ Family indet. \\ Genus Carolowilhelmina Carls, 1995
}

Derivatio nominis: Carolo-Wilhelmina is the name of the Technische Universität Braunschweig after its founders, the dukes Carl and Wilhelm of Braunschweig. The generic name was chosen in 1995 on occasion of the $250^{\text {th }}$ anniversary of the foundation of this university. Grammatical gender: feminine.

\section{Diagnosis: As for type species, by monotypy.}

Type species: Carolowilhelmina geognostica Carls, 1995.

\section{Carolowilhelmina geognostica Carls, 1995} Figs. 3-18

Derivatio nominis: neo-Latin adjective, feminine gender, of the ancient term used instead of "geological". The name was given in order to commemorate, because of the closure of the subject Geology-Palaeontology at the Technical University Carolo-Wilhelmina in Braunschweig, that this subject had a long and laudable history since the early days of the Carolo-Wilhelmina.

\section{Diagnosis}

A large arthrodire with long tubular rostral plate bearing rare small lateral spines arranged into sinuous row; extensive posterior median lobe of rostral plate sutures with slender pineal plate; postnasal plates small, in contact with preorbital plates and anteriorly with rostral plate, not participating in the orbital margins; right and left supraorbital and central sensory lines are continuous across median suture of central plates; suborbital branch of infraorbital sensory line probably reaches anteriorly ventral surface of rostral plate and continues on it further along the plate; inferognathal low, without teeth.

Holotype: monotype MPZ 95/174, incomplete skull with inferognathals and parasphenoid, deposited in the Museo Paleontológico de la Universidad Zaragoza; Zaragoza, Spain.

Type locality: Eastern slope about $3 \mathrm{~m}$ above the creek Río Moyuela $=$ Río Santa Maria, $190 \mathrm{~m} \mathrm{~S}$ of the decayed mill Molino Bajo, $2.20 \mathrm{~km} \mathrm{~N}$ of the Church of Monforte de Moyuela; SE quadrant of Mapa Topográfico Nacional 1:25.000 sheet 466 (Blesa) IV (Blesa), X: 667.110, Y: 4549.050; Mapa Geológico de España 1:50.000 sheet 466 (Moyuela) X: 824.700, Y: 722.470 (Fig. 2).

Type stratum: Moyuela Formation, upper limestone bed of Member E of Wang (1987, 1991), under 4.2 m of black shales that form the Member F, the top of the formation. The type stratum is a sparitic limestone, a comparatively old pumilio bed full of tiny brachiopods; its conodonts indicate the kockelianus Zone; it consists of lenticular bodies of limestone the peculiar shapes of which are due to slumping; it is about $8-16 \mathrm{~cm}$ thick and forms the top of a total of 60 to $65 \mathrm{~cm}$ of few layers of marl and limestone nodules that constitute Member E, which is exposed above $1.75 \mathrm{~m}$ of marly styliolinid shales of Member D (Fig. 2). The overlying Member F corresponds to the Kacak Event.

\section{Description}

The incomplete skull under description, MPZ 95/174 (Figs. 3-9), is the only specimen. It lacks the anterior end, i.e., the anterior portion of a very long tubular rostral $(\mathrm{R})$ plate and most of the posterior portion of the skull-roof. The pineal (P) plate, paired preorbital ( $\mathrm{PrO})$, postorbital (PtO), and central (C) plates can be recognized in the skull-roof. The small fragmentary right postnasal $(\mathrm{PN})$ plate is in its anatomical position anteriorly to the orbit. The anterior portion of the left marginal (M) plate is preserved, whereas the right marginal, paired paranuchal $(\mathrm{PNu})$ plates, and the nuchal $(\mathrm{Nu})$ plate are missing. Of the cheek plates, the specimen shows the right and left suborbital (SO) plates, the left one being more complete. Under the supraorbital vaults (suo.v, Fig. 9B) right and left sclerotic rings are visible; the right one is more completely preserved. The lower jaw bones, the inferognathal (IG) plates, are present, but are not in anatomical position: the right inferognathal is situated under the left suborbital. The left inferognathal is partly exposed in a gap formed along the midline of the skull and is pushed somewhat upward and forward. The gap was originally occupied by the long posterior lobe of the rostral plate.

To the left of the anterior end of the left inferognathal the edge of an elongated bone was visible (Fig. 3a), which 

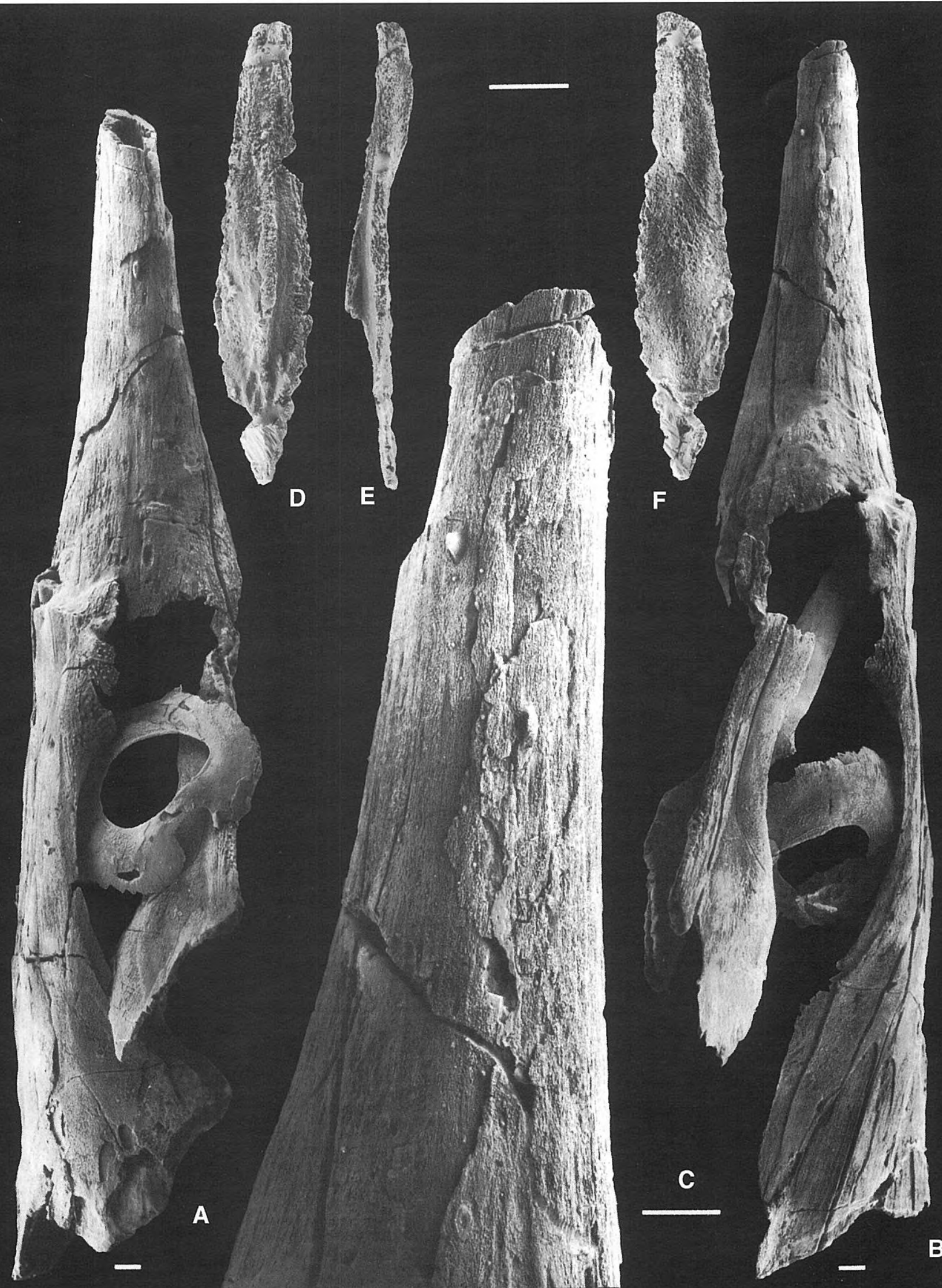

Figure 4. Carolowilhelmina geognostica Carls, 1995. Skull, Holotype MPZ 95/174. a. Right lateral view of the skull. b. Left lateral view of the skull. c. Left side of the rostrum. d-f. Parasphenoid in d, dorsal view, e, right lateral view, and $\mathrm{f}$, ventral view. Scale bars $=1 \mathrm{~cm}$. 


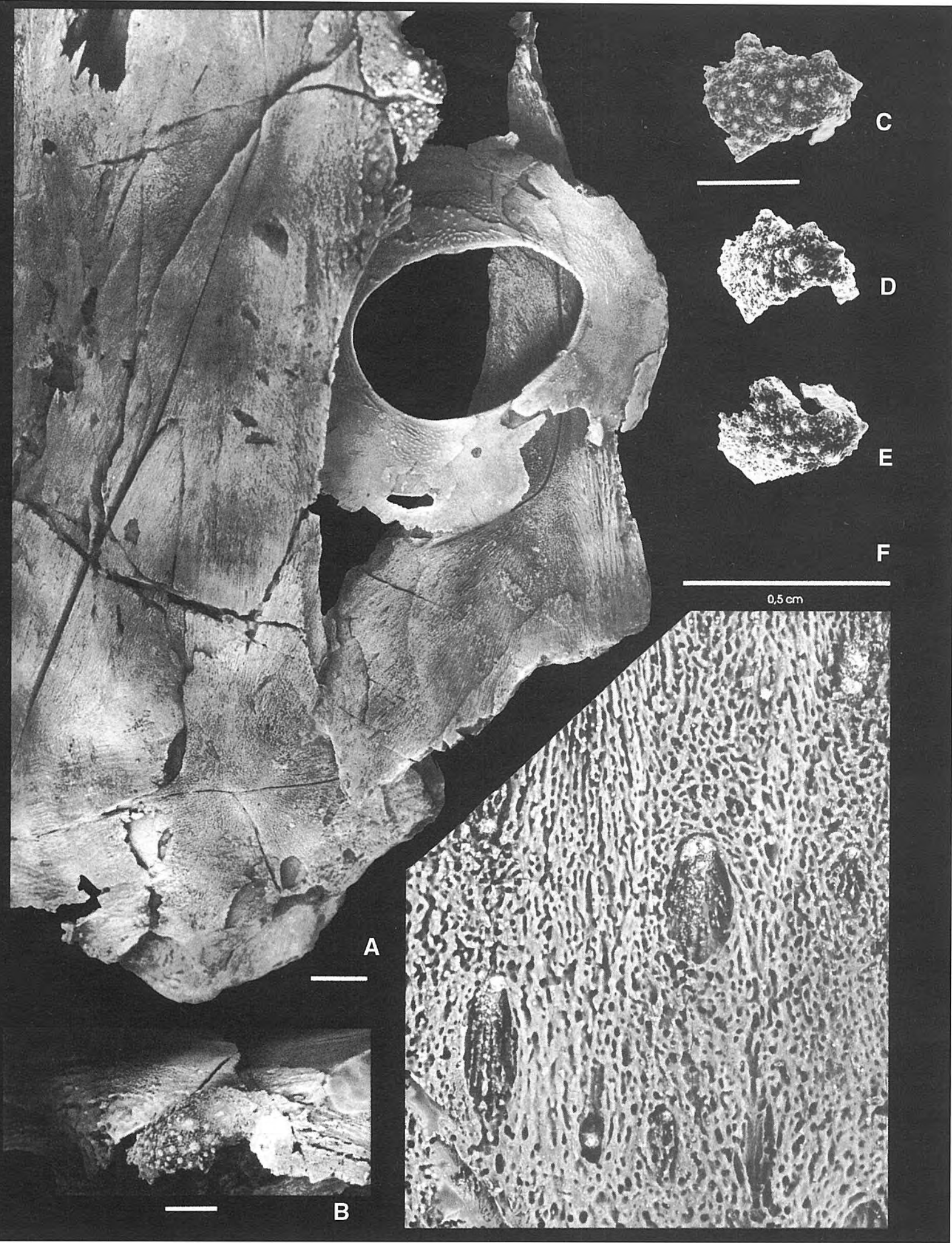

Figure 5. Carolowilhelmina geognostica Carls, 1995. Skull, Holotype MPZ 95/174. a. Detail of the right side of the skull, showing contacts of the postnasal, preorbital, central, and postorbital plates; to the right are the suborbital plate and sclerotic ring. b. Right postnasal plate, anterior view. c-e. Isolated left postnasal plate in c, anterior view, d, lateral view, and e, posterolateral view. f. Ornamentation of the dorsal side of the rostral plate (for location see Fig. $12 \mathrm{~A}$ in the text). Scale bars for a-e $=1 \mathrm{~cm}$, for $\mathrm{f}=0.5 \mathrm{~cm}$. 


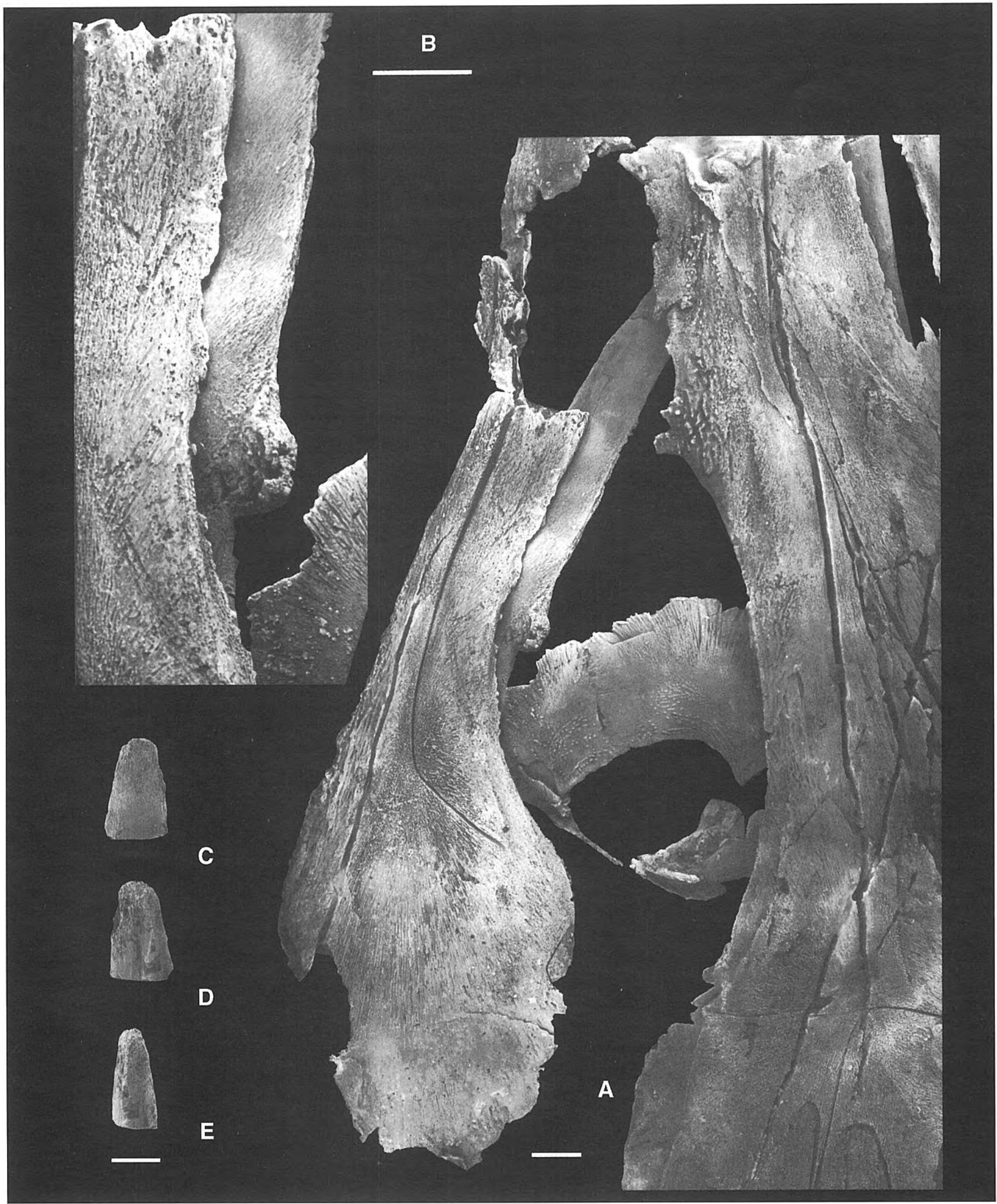

Figure 6. Carolowilhelmina geognostica Carls, 1995. Skull, Holotype MPZ 95/174. a. Left side of the skull showing plates surrounding the orbital opening: the preorbital, postorbital, suborbital plates and the sclerotic ring. From under the left suborbital plate the anterior portion of the right inferognathal plate is visible. $\mathbf{b}$. The same region of the skull as in a, magnified and showing lingual and dorsal margins of the right inferognathal. The toothless anterior portion of the inferognathal plate ends posteriorly with a spongy "knob". c-e. Anterior end of the left inferognathal, in c, lingual view, d, labial view, and e, dorsal view. Scale bars $=1 \mathrm{~cm}$. 
appeared to be an almost completely preserved parasphenoid (Psp; Figs. 4d-f, 18) lying in the sediment with its anterior end turned backwards. Treatment of the skull with acid yielded some isolated bones and fragments including the left postnasal (Fig. 5c-e) and a fragmentary left(?) submarginal (Fig. 7d, e).

The skull-roof shows some cracks but is not strongly deformed (Figs. 3a, 8, 9). The widest crack crosses the posterior part of the rostral plate and the anterior ends of the preorbital plates, respectively. As a result, the rostral plate is slightly bent downward and turned to the right relative to the major part of the skull (Figs. 3a, 4a,b). The anterior portion of the rostral plate is also cracked, but after restoration it appears to be dorsoventrally flattened and oval in cross section (Fig. 13). One narrower crack begins approximately at the ossification centre of the left preorbital plate and runs obliquely through the left central plate. The right side of the skull-roof (Fig. 4a) is less flattened than the left one and may have preserved its natural curvature. The central part of the skull-roof is comparatively flat and slightly concave. The skull-roof flanks formed by the postorbital plates were hanging almost vertically (Fig. 14). The angle between the middle part of the skull-roof and the lateral face of the right postorbital is about $110^{\circ}$. The preserved part of the skull is $43 \mathrm{~cm}$ long along its midline. The width of the skull-roof on the level of the ossification centres of the postorbital plates is $16 \mathrm{~cm}$ (deformation of the left side being eliminated). The right side posteriorly of the postorbital ossification centre is $6 \mathrm{~cm}$ deep. The rostral plate is $6 \mathrm{~cm}$ high and $8 \mathrm{~cm}$ wide at its posterior end. The skull-roof is rather thin for such a large skull. The rostral plate is $3 \mathrm{~mm}$ thick at its broken anterior end. The posterior part of the skull-roof is thinner: $1.5-2 \mathrm{~mm}$ approximately on the level of the postorbital ossification centres. The supraorbital vaults are exceptional reaching 2.7 $\mathrm{cm}$ in thickness. The suborbital plates vary in thickness from $0.5 \mathrm{~mm}$ at the dorsal margin of the postorbital lamina to 3-7 $\mathrm{mm}$ along the ventral margin. The inferognathal is up to 9 mm thick.

Sutures of the skull-roof plates are unequally developed. Some of them, e.g., between the preorbitals and centrals, and between the postorbitals and marginals are clearly visible (Figs. 3, 4b, 5a, 6a). The contact line of the pineal plate with the centrals is also rather easily traceable (Figs. 3a, 7c). The other sutures are less clear and some are hard to identify, for example those of the rostral plate and the preorbital plates or the suture between both central plates. The latter plates have a suture which is slightly sinuous anteriorly and strongly sinuous between the supraorbital and central sensory line grooves and behind them. Some plates may suture by rather wide overlapping, e.g., the postorbital and marginal plates (Fig. 5a). The preorbital plates show narrow overlap margins for the extensive posterior median lobe of the rostral plate; the latter has a zigzag suture with the pineal plate (Figs. 3a, 6a).

Sensory lines. The skull-roof and the suborbital plate (Figs. 3-6, 15) are grooved by supraorbital (soc), central (csc), and infraorbital (ioc) sensory lines. The infraorbital sensory line has three branches: otic (ioc.ot), postorbital (ioc.pt), and suborbital (ioc.sb). The sensory line grooves are very narrow at the ossification centres of plates and considerably wider in their marginal areas, particularly in the anterior portions of the plates, e.g., in the preorbital and central plates, in the left marginal plate and in the suborbital plate (Figs. 5a, 6a). A feature of note is that supraorbital and central sensory lines unite at the midline of the skull, forming a straight double line (Fig. 5). The ventral side of the rostral plate shows another unusual character consisting of well-developed sensory line grooves, which probably are the suborbital branches of the infraorbital sensory lines (Fig. 7a).

The ornamentation of the skull is variable; five types of it can be distinguished. (1) Most of the skull-roof plates as well as the suborbital and submarginal plates lack tubercles. The plates have an open, trabecular structure (Figs. 3b, 6a, 7c,d). (2) The preorbital plates anteriorly to the orbital openings show a special kind of ornamentation consisting of rather rough irregular pits and grooves (Figs. 3b, 5a,b, 6a). (3) A well-developed tuberculated ornamentation occurs on the postnasal plates (Figs. 3b, 5a-e). The plates bear conical or round-topped tubercles with spongy branching bases. The largest tubercles with a diameter of 3-3.5 mm are faced anterolaterally. (4) The sclerotic plates show a very fine ornamentation of tiny tubercles and ridges (Figs. 5a, 6a). (5) The ornamentation of the rostral plate is quite unusual. It is either trabecular or pitted, but it includes also numerous tubercles scattered over the plate surface. The tubercles may, in rare cases, reach the size of the largest tubercles on the postnasals; most of them are, however, much smaller. Quite a number of tubercles are situated in oval longitudinal depressions; obviously these belong to an earlier generation (Figs. 5f, 7a,b, 12). The posterior end of the rostral plate anteriorly and laterally of the gap is roughly grooved (Figs. $3 a, 4 a, b)$.

The rostral plate (R) (Figs. 3a, 4a-c, 5f, 7a,b, 8-13) is a large and tubular bone. At the broken anterior end it is oval in outline and dorsoventrally flattened (Fig. 13). The plate widens gradually backwards. The posterior end of the plate is somewhat wider than high, its dorsal and especially its ventral surfaces being rather flat and lateral sides moderately convex. On the dorsal side, the posterior margin of the plate is deeply embayed, meeting the long wedge-shaped anterior lobes of the preorbital plates. The rostral plate has a long median lobe that comes into contact with the pineal plate at the level of the ossification centres of the preorbital plates.

The bone is missing in the posterolateral parts of the rostral plate, but it is preserved along the sensory line grooves on both sides of the skull (Figs. 4a,b, 9). The grooves fork at some distance from the broken anterior end of the rostral plate (Fig. 7a). Not far from the posterior margin of the rostral plate they curve ventrolaterally. It is supposed that these grooves continue the suborbital branches of the infraorbital sensory lines. When restored, the branches in the rostral plate follow the direction of the segments of the same branch in the suborbital plates (Fig. 11). Hardly visible growth lines subparallel to the broken posteroventral margin (Fig. 7a) seem to indicate that an internasal plate or the anterior margin of this plate could be incorporated into the rostral plate.

There are small flat spines on both sides of the rostrum (Figs. 4a-c, 7a, 9: 1.s.). They are oval at their bases and are 


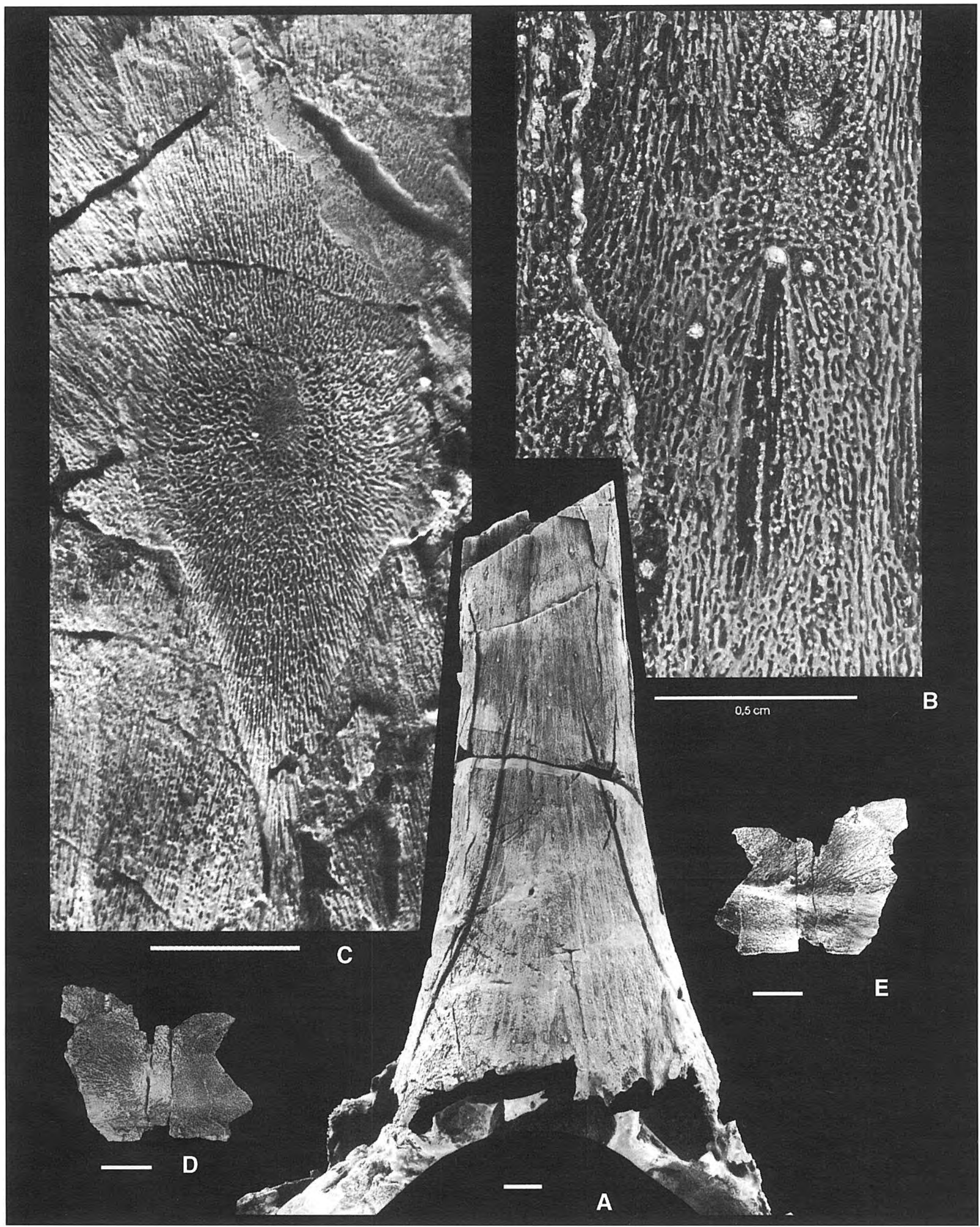

Figure 7. Carolowilhelmina geognostica Carls, 1995. Skull, Holotype MPZ 95/174. a. Rostral plate, ventral view. b. Ornamentation of the dorsal side of the rostral plate (for location see Fig. 12B). c. Pineal plate, posterior portion. Radiating bone lamellae surround a smooth area, which is the ossification centre of the plate. d-e. Fragment of the left submarginal plate, in d, external view, and e, visceral view. Scale bars for $\mathrm{a}, \mathrm{c}-\mathrm{e}=1 \mathrm{~cm}$, for $\mathrm{b}=0.5 \mathrm{~cm}$. 


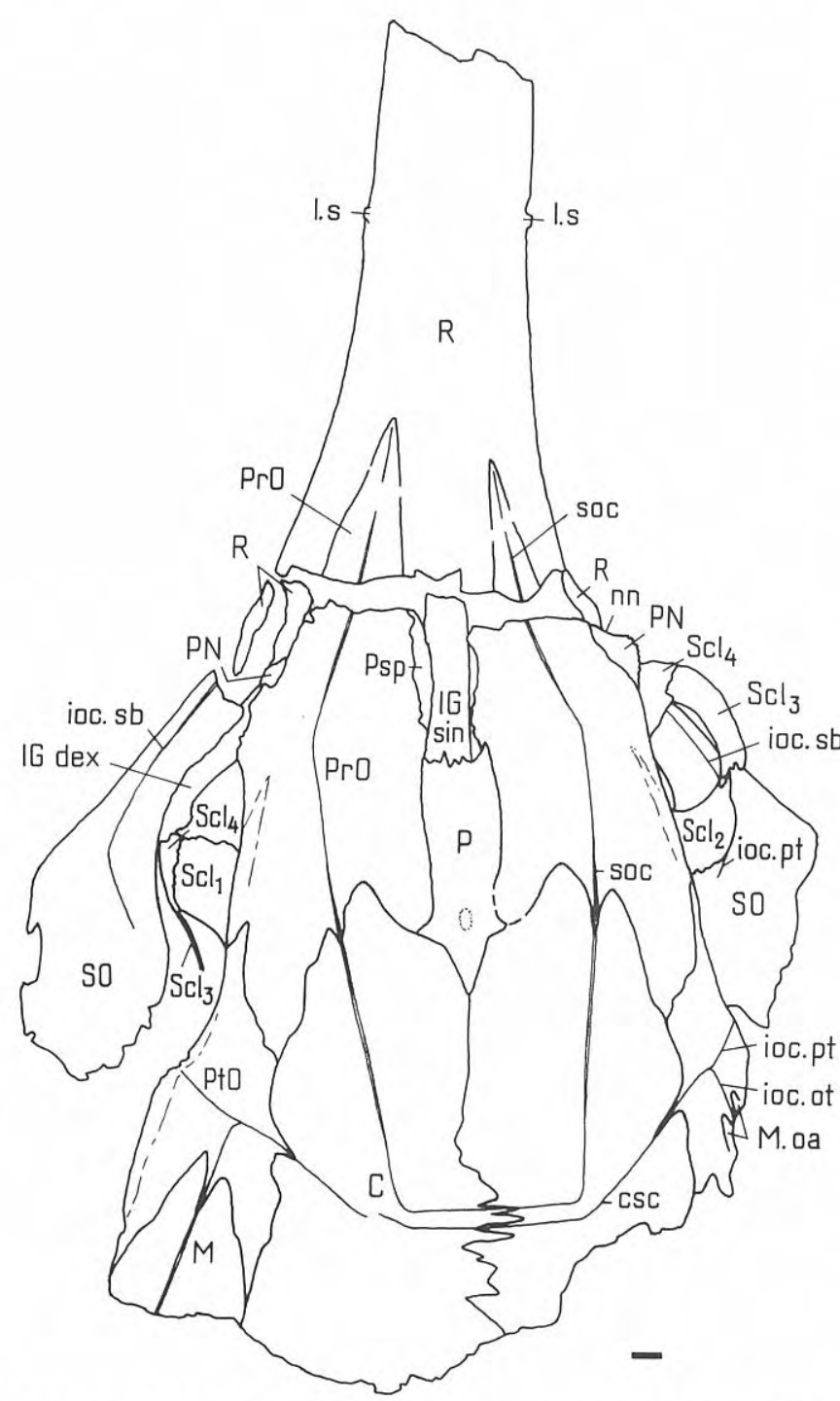

Figure 8. Carolowilhelmina geognostica Carls, 1995. Holotype MPZ 95/174. Skull, dorsal view. Key to Fig. 3a. Scale bar $=1 \mathrm{~cm}$.

situated in depressions of similar shapes. The spines are rare and are arranged into sinuous rows. The left side of the rostral plate shows five spines or their bases.

The pineal plate $(\mathrm{P})$ (Figs. 3a, 7c, 8, 10) is long and narrow and has sutures with the rostral, preorbital, and central plates. It has small posterolateral lobes. On their level the bone lamellae concentrate around an oval and smooth patch that marks the ossification centre. No pineal opening is present.

The preorbital plates (PrO) (Figs. 3a, 4a,b, 5a,b, 6a, 811) are large and considerably longer than wide. They do not meet in the midline, being separated by the rostral and pineal plates. They have long anterior and posterolateral lobes and a shorter posteromesial lobe reaching the area between the pineal and central plates. Anterior to the orbital opening, the plates have a suture with the postnasal plates along a very narrow overlap margin (Fig. 9B: PN.oa). Posteriorly to the postnasal plate the supraorbital vault (suo.v) becomes gradually thicker on the visceral side of the left preorbital plate. The anterior end of the vault is marked with a triangular lateral process that bears a specific ornamentation of irregular grooves and pits and hangs vertically (Fig. 5b).

Postnasal plate (PN). Both somewhat fragmentary right and left postnasal plates are preserved, the former in its anatomical position (Figs. 3, 4a, 5a,c-e, 7a). The plate is small, with a cone-shaped anterolateral portion and an elongated slightly convex posterior portion. Tubercles occur on most of its external surface; the largest ones are faced anterolaterally. Mesioventrally to this largely tuberculated area, the anterior edge of the plate is bent down and notched for a nostril (Figs. 5b, 7a, 9A: nn). The left preorbital plate has a narrow overlap area for the postnasal plate (Figs. 6a, 9B: PN.oa). In front of it, there is a small roughly triangular fragment of the plate fused with the preorbital. Probably it is the anterior portion of the left postnasal plate (Fig. 9B: PN). The postnasal plates faced anterolaterally (Fig. 10) and did not participate in the orbital margin (Fig. 11).

The central plates $(\mathrm{C})$ are large but do not possess long lobes like those of the preorbital or postorbital plates (Figs. $3 \mathrm{a}, 5 \mathrm{a}, 8,10)$. Their anterior and lateral margins are notched at the spots where the supraorbital and central sensory line grooves cross the sutures of the central, preorbital, and postorbital plates. Along the midline the central plates have a suture that becomes gradually more complicated in the posterior part of the plates. It is strongly sinuous between the parallel grooves of the above sensory lines. The suture is not easily traceable because of the poor preservation of the external surface of the posteromedian portion of the skull.

The postorbital plates $(\mathrm{PtO})$ are much smaller than the preorbital and central plates with which they have a suture (Figs. 3a, 4a,b, 6a, 8-11). The plates have long and narrow lobes. The anterior lobe has a firm contact with the preorbital plate; the posteromesial lobe fades out between the marginal and central plates. The postorbital plates are transversally convex. Their ventrolateral edges bear very clearly developed and wide overlap margins (Figs. 4b, 9, 14: oa?). When the skull was restored in lateral view (Fig. 11), it appeared that the suborbital plates could hardly come into contact with the margins of the postorbital plates above them; thus, there should be a gap between the suborbital and postorbital plates.

Marginal plate (M). Only the anterior portion of the left marginal plate is partly preserved (Figs. 3a, 4b, 8-11). Its anterior end forks similarly to the anterior ends in the central plates. The overlap area of the marginal plate is preserved on the right postorbital plate (M.oa).

Suborbital plate (SO). the left suborbital plate is more completely preserved than its antimere (Figs. 3a, 4a,b, 5a, 15). The plate consists of the mostly high and thin postorbital lamina and the slender and more massive suborbital lamina. The external surface shows the bone structure of thin lamellae that concentrate at the ossification centre. Through this centre the postorbital branch of the infraorbital sensory line (Fig. 15: ioc.pt) runs toward the dorsal margin of the plate without reaching it. The suborbital branch of the same line (ioc.sb) is running to the anterior end of the suborbital lamina. The lamina ends rather abruptly, being still high. On the visceral surface (Fig. 15B) the ventral margin bears a thickening (v.th) that is wider posteriorly and fades out at the anterior end of the plate. The 

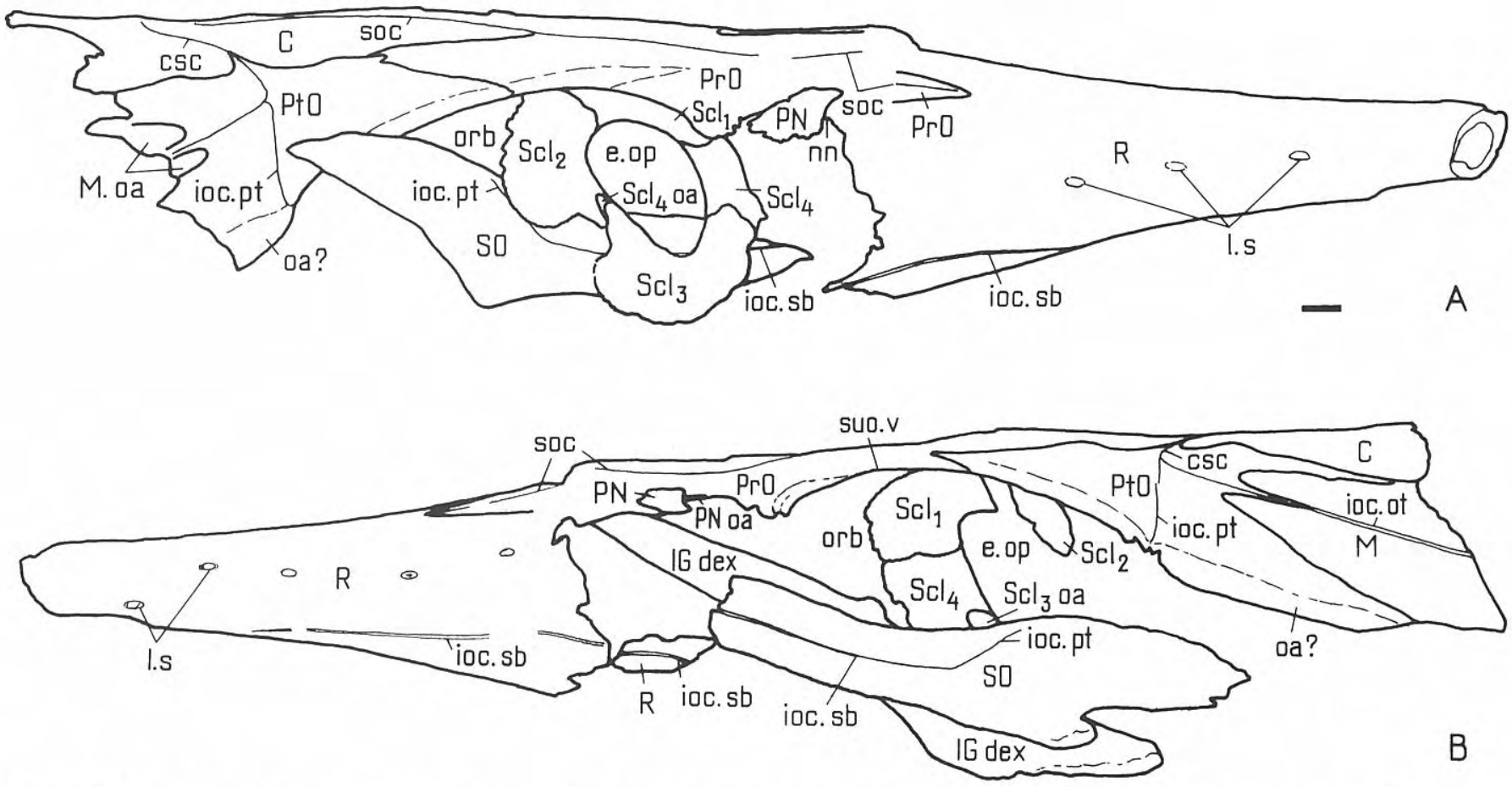

Figure 9. Carolowilhelmina geognostica Carls, 1995. Holotype MPZ 95/174. Skull. A. Right lateral view. Key to Fig. 4a. B. Left lateral view. Key to Fig. 4b. Scale bar $=1 \mathrm{~cm}$.

thickening is dorsally grooved (gr). Under the orbit the plate is also somewhat thicker (th). The bone surface on the ventral margin is rough.

Submarginal plate (SM). A flat piece of bone about 3.5 $\mathrm{cm}$ long and $3 \mathrm{~cm}$ wide is supposed to be a fragment of the left submarginal plate (Fig. 7d,e). On its external surface (Fig. 7d) the bone trabeculae radiate from the growth centre situated in the lower (?) portion of the plate where it has its maximum thickness of $3.5 \mathrm{~mm}$. The plate has a shallow groove along the ventral (?) margin. On the visceral surface (Fig. 7e) a narrow ridge runs obliquely to the broken posterior (?) margin; the ridge has a short branch directed anteriorly.

The sclerotic ring (Figs. 3a, 4a,b, 5a, 6a, 16) consists of four fairly wide sclerotic plates: anterior $\left(\mathrm{Scl}_{1}\right)$, dorsal $\left(\mathrm{Scl}_{2}\right)$, posterior $\left(\mathrm{Scl}_{3}\right)$, and ventral $\left(\mathrm{Scl}_{4}\right)$. The position of the plates in the orbital opening is given tentatively (Fig. 11 ), as the rings of the right and left eyes are dislodged differently. In the right ring all plates are present and almost complete. The sizes of the plates are unequal. The ventral $\left(\mathrm{Scl}_{4}\right)$ is the smallest and the posterior plate $\left(\mathrm{Scl}_{3}\right)$ the largest. The plates are transversally convex. Closer to the ring centre their external surfaces bear very fine tubercles which fuse into ridges. The tuberculated portions of the plates are the thickest (about 2.5-3 mm). Towards their outer margins the sclerotic plates become extremely thin and finely grooved. The interlock of the sclerotic plates is complicated and might be rather firm. The ventral plate is widely overlapped by the anterior plate and also by the posterior plate (Fig. 9B: $\mathrm{Scl}_{3}$.oa) and shows deep pockets at the orbital margin. The posterior and dorsal plates have a strongly sinuous suture in which the posterior plate overlaps the dorsal one at the eye opening and underlies its edge at the outer margin of the ring. The upper edge of the dorsal plate overlaps the anterior plate. The eye opening (Fig. 16: e.op) is large and ovoid in outline. The sclerotic ring occupies the central major part of the orbital opening.

The inferognathal plate (IG) (Fig. 17) has been restored using the right plate lying in close proximity to the left suborbital plate (Figs. 3a, 4b, 6a,b) and the anterior end of the left plate (Fig. 6c-e). The posterior portion of the plate is exposed under the suborbital plate. The plate is over $20 \mathrm{~cm}$ long, up to $3.2 \mathrm{~cm}$ high and $0.8-0.9 \mathrm{~cm}$ thick. In dorsal view (Fig. 17B) it has a sinuous shape. The inferognathal plate has a bar-like, slightly mesially curved anterior portion or functional division (fd) and a somewhat higher posterior portion or blade (bd). The latter is bent laterally. The functional division has a bluntly tapering end that is rough on its labial side (Fig. 6d). There are no traces of teeth. Along the dorsal edge on the outer side of the functional division runs a narrow ridge, and there is a shallow groove (Fig. 17A: gr) parallel to the ridge. The anterior portion of the plate ends with a shallow oblong "knob" (kn) of spongy structure. The blade has a rather deep groove along its ventrolateral margin for the mentomeckelian bone (Fig. 17A: gr.Mm). The labial surface at the posterior end shows a number of weak parallel ridges. The lingual face of the blade is quite smooth.

The parasphenoid (Psp) is a small slender bone resembling in shape a willow leaf (Figs. 4d-f, 18). The bone is preserved almost in its full length that could be about 6.5 $7 \mathrm{~cm}$ (the anterior end is incomplete). The maximum width is $1.2 \mathrm{~cm}$ in the posterior portion of the plate. The parasphenoid is rather flat, slightly asymmetrical and of simple structure. On the dorsal side it has a narrow crest that is higher posteriorly and ends with a median process (Fig. 


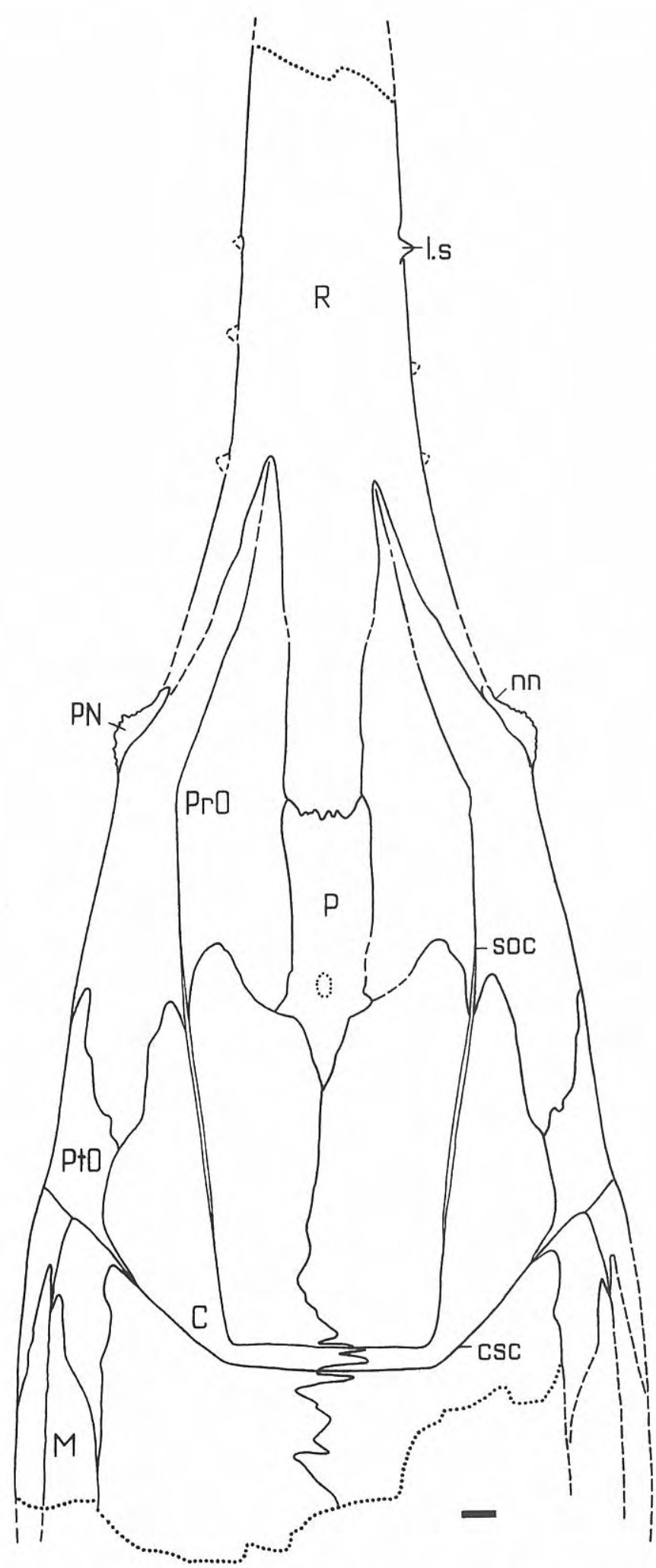

Figure 10. Carolowilhelmina geognostica Carls, 1995. Skull. Reconstruction, dorsal view. Scale bar $=1$ $\mathrm{cm}$.

18: m.pr); the crest is T-shaped in cross section. The ventral side has an oval posterior depression and a shallow median crest (cr.m) in the pre-hypophysial part (pa.phyp) of the parasphenoid. The bone has no foramina or tubercles.

\section{COMPARISON AND DISCUSSION}

Long-snouted genera are comparatively rare among arthrodires. Six of the eight known genera come from the Frasnian (Late Devonian). These are the early Frasnian camuropiscids Camuropiscis, Tubonasus, and Rolfosteus from Gogo (Western Australia) and the late Frasnian brachydeiroids Leptosteus, Brachydeirus, and Oxyosteus from Wildungen (Germany) and from some other localities, Erie County (New York) and Holy Cross Mountains (Poland) (Denison, 1978). Only two genera are known from the Middle Devonian: the early or middle Givetian Maideria from Morocco and the late Eifelian Carolowilhelmina from Spain.

Almost all the listed brachythoracid arthrodires are of moderate size: the length of the skull varies from 6 to 12 $\mathrm{cm}$, exceeding $18 \mathrm{~cm}$ only in Oxyosteus. Carolowilhelmina is exceptional: the incomplete length of the skull is $43 \mathrm{~cm}$, but the full skull length of this fish is probably more than $55 \mathrm{~cm}$. The length of the snout varies in the arthrodires mentioned above. The representatives of three genera, Carolowilhelmina, Rolfosteus, and Oxyosteus are particularly long-snouted.

In Carolowilhelmina the cross sections of the anterior end of the tubular rostral plate (Fig. 13) and of the skullroof on the level of the ossification centres of the postorbital plates (Fig. 14) show that the skull was dorsally and the rostrum dorsoventrally flattened. The skull of Oxyosteus could be somewhat roof-shaped judging by the cross section of the trunk-shield (Gross, 1932: fig. 18C). In Rolfosteus the skull-roof was perhaps moderately convex like in Latocamurus (cf. fig. 6 in Dennis and Miles, 1979b and fig. 15 in Long, 1988a).

The sutures of the skull-roof plates (Figs. 8, 10) of Carolowilhelmina are comparatively simple except the zigzag sutures between the rostral and pineal plates and the right and left central plates in their posterior portion. Posteriorly more complicated sutures of the central plates can be observed in several arthrodires, e.g., in homosteids (Denison, 1978: fig. 51A,C) or the plourdosteid Compagopiscis (Gardiner and Miles, 1994: fig. 4). Fairly characteristic are the fork-like contact lines of the central and preorbital plates and the marginal and postorbital plates. The fork-like suture of the marginal and postorbital plates is also characteristic of several coccosteids (Denison, 1978: fig. 57B, D, E).

In Carolowilhelmina the supraorbital (soc) and central (csc) sensory lines of the right and left sides fuse with one another at the midline of the skull, forming a double line (Figs. 8,10). That is a unique character of the new genus. So far, the central sensory lines were known to be continuous across the median suture of the central plates in Dickosteus, Watsonosteus (Denison, 1978: fig. 57), Jiuchengia (Wang and Wang, 1983: Fig. 1) and Heterostius (Mark-Kurik, pers. observ.). Anteriorly, the supraorbital sensory lines (soc) reach the narrow pointed ends of the preorbital plates but do not continue on the rostral plate as in Maideria (Lelièvre, 1995) or Holonema (Miles, 1971; Gardiner and Miles, 1990). The probable suborbital branches of the infraorbital sensory lines 


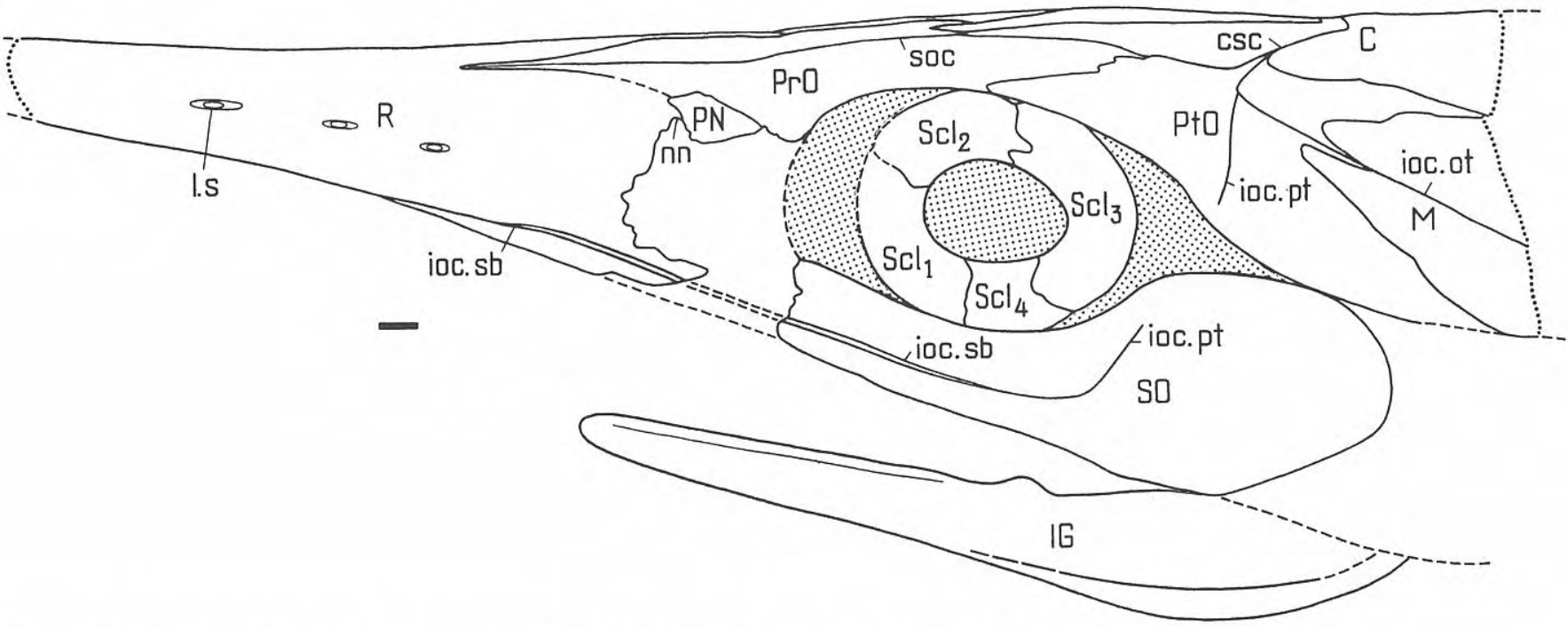

Figure 11. Carolowilhelmina geognostica Carls, 1995. Skull. Reconstruction, left lateral view. Scale bar $=1 \mathrm{~cm}$.

(ioc.sb) continue on the ventral surface of the rostral plate, their anterior ends almost meeting one another in the middle (?) part of the rostrum. In the other longsnouted taxa, Tubonasus and Rolfosteus, the same branches do not run farther from the suborbital laminae of the suborbital plates (Dennis and Miles, 1979b). In these arthrodires the branches could probably meet under the short snout and nostrils as demonstrated in the restoration of the skull of Latocamurus (Long, 1988a: fig. 15) or in Pholidosteus (Stensiö, 1963: fig. 72).

Where present, as in the rostral and postnasal plates, the ornamentation of Carolowilhelmina is strikingly variable. However, most of the plates lack tubercles. In the rostral plate the mainly small tubercles are scattered over the plate surface and are situated in elongated depressions. In a way, this ornamentation can be compared with that of Rolfosteus, showing in places double structures (Dennis and Miles, 1979b: fig. 16), i.e., an earlier generation of tubercles is overgrown by the younger layer of bone. The thorn-like lateral spines of the rostral plate of Carolowilhelmina have no analogues in the other arthrodires.

The rostral plate of Carolowilhelmina is long and straight (not upturned as in Maideria; Lelièvre, 1995), longer than in Tubonasus and perhaps even longer than in Rolfosteus (Dennis and Miles, 1979b). It is tubular and could have had a round end like that of Maideria. It is hard to believe that the plate was anteriorly opened (Dennis and Miles, 1979b) or that there was an apical opening (Long, 1988b) like in Tubonasus or Rolfosteus. According to Stensiö (1963), the rostral plate of brachydeiroids (Leptosteus, Brachydeirus, Oxyosteus) consists of two laminae, the dorsal and the anterior descending laminae. In Oxyosteus the rostral plate is not tubular and is filled with cartilaginoid material (Gross, 1932). As mentioned, the supraorbital sensory lines (soc) in Carolowilhelmina do not run from the preorbital plates to the rostral plate. In the posterolateral part of the rostral plate the bone is missing in Carolowilhelmina as in Rolfosteus and Tubonasus (Dennis and Miles, 1979b). At the anterior edge of the orbit the bone is lacking in Carolowilhelmina, but in Rolfosteus and Tubonasus the anterior margin of the orbit is occupied by the postnasal plate and the dermal plates completely surround the orbital opening. In Holonema (Miles, 1971) the anterior and middle divisions of the orbital opening show no bones. An explanation given by Miles is that in this part of the skull a regressive development of the exoskeleton took place.

Weak and interrupted growth lines parallel to the posterior margin of the rostral plate on its ventral side perhaps show that there was an internasal plate in Carolowilhelmina similar to that of Maideria (Lelièvre, 1995: fig. 6B). Also in Rolfosteus the internasal plate could be incorporated into the tubular rostral plate, as supposed by Dennis and Miles (1979b).

Like in Rolfosteus, Camuropiscis (Dennis and Miles, 1979a), and Kendrickichthys (Dennis and Miles, 1980) the slender pineal plate of Carolowilhelmina has no pineal opening. According to Denison (1978), a pineal foramen is rare in placoderms.

The preorbital plate of Carolowilhelmina resembles in its configuration somewhat that of Kendrickichthys (Dennis and Miles, 1980: fig. 13), but it is narrower, in particular anteriorly, and longer. The supraorbital sensory line (soc) runs in a similar way in both genera turning to the anterior end of the preorbital plate (instead of being directed to the postnasal plate).

The small postnasal plate of Carolowilhelmina (Figs. $10,11)$ can be compared with the rather small equivalent plate of Brutonichthys (Dennis and Miles, 1980: fig. 4E,F). The plates of both Brutonichthys and Carolowilhelmina have shallow nasal notches (the postnasal plate of Brutonichthys lacks ornamentation). In Carolowilhelmina the interfenestral process, known in Brutonichthys and well developed in Coccosteus (Miles and Westoll, 1968: fig. 12a-c), cannot be identified. The postnasal plate of Carolowilhelmina slightly overlaps the preorbital plate (Fig. 9B), whereas in Brutonichthys the plate has no contact face for the preorbital plate. In 


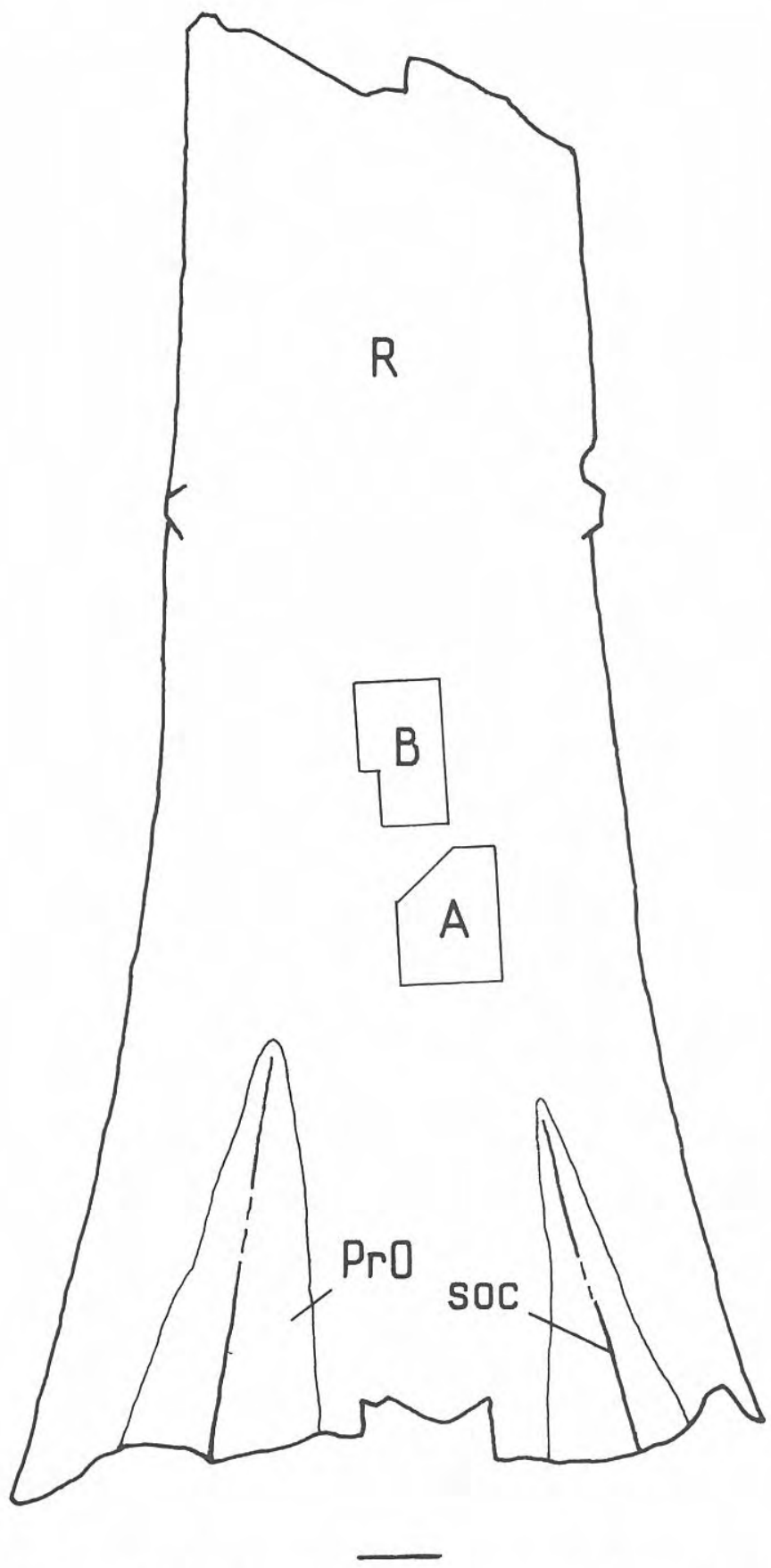

Figure 12. Carolowilhelmina geognostica Carls, 1995. Rostral plate. Key to the ornamentation of the dorsal side. For A see Fig. 5f; for B see Fig. 7b. Scale bar $=1 \mathrm{~cm}$.

Carolowilhelmina the anterolaterally conical postnasal plate could house a funnel-shaped nasal capsule similar to that of Eastmanosteus calliaspis (Dennis-Bryan, 1987: fig. 16A-C).

In Carolowilhelmina the nasal notch (Figs. 9A, 11, $\mathrm{nn}$ ) occurs between the postnasal and rostral plates like, e.g., in Incisoscutum (Dennis and Miles, 1981), Harrytoombsia (Miles and Dennis, 1979), Gogosteus and Latocamurus (Long, 1988a, 1994). In Tubonasus with a comparatively large postnasal plate the position of the notch is unknown. In Rolfosteus the notched margin of a smaller postnasal plate could be the posterior margin of the anterior external nasal opening; the external nostrils are situated between the posteroventral edge of the rostral plate and the postnasal plate (Dennis and Miles, 1979b). In the above arthrodires the suborbital plate articulates with the postnasal plate, whereas in Carolowilhelmina considerable space remains between the anterior end of the suborbital and the postnasal plate. In camuropiscids with fairly large postnasal plates (Tubonasus, Rolfosteus, Latocamurus) the plate participates in the orbital margin to different degrees; the participation is particularly significant in Camuropiscis (Dennis and Miles, 1979a). In this aspect Carolowilhelmina is quite exceptional: its small postnasal plate does not reach the orbital opening and has not a sensory groove either.

The postorbital and central plates of Carolowilhelmina show some similarity to the equivalent plates of Kendrickichthys (Dennis and Miles, 1980). However the postorbital plate of Carolowilhelmina (Figs. 10, 11) has a long posterior process situated between the central and marginal plates. The central plates have the characteristic fusion of the supraorbital and central sensory lines, respectively, at the zigzag suture of the right and left plates, which is not known in any other arthrodire. It is possible that the postorbital plate had no direct contact with the suborbital plate and that there was a gap between these plates, as it is known, e.g., in Eastmanosteus galliaspis (Dennis-Bryan, 1987: fig. 5), in Torosteus, and in Harritoombsia (Miles and Dennis, 1979; Gardiner and Miles, 1990).

The marginal plate of Carolowilhelmina (Figs. 10, 11) articulates with the postorbital plate similarly to the equivalent plates in the coccosteomorphs Coccosteus, Watsonosteus, and Torosteus (Denison, 1978; Gardiner and Miles, 1990), forming a fork-like suture.

The suborbital plate of Carolowilhelmina (Figs. 11, 15) shows no firmly fixed articulation with the skull-roof as do the equivalent plates in Rolfosteus, Tubonasus (Dennis and Miles, 1979b), and Camuropiscis (Dennis and Miles, 1979a). There must have been a roughly triangular gap between the sclerotic ring and the suborbital and postorbital plates. A gap of similar configuration is figured in Leiosteus and Hadrosteus (Stensiö, 1963: figs. 102C, 106C). Unlike camuropiscids, the postorbital branches of the infraorbital sensory lines (ioc.pt) of the postorbital and suborbital plates had no contact. In the suborbital plate of Hadrosteus the upper branch is short and does not run much further from the ossification centre of the plate. The gap behind the sclerotic ring of Carolowilhelmina resembles those of Gymnotrachelus (Carr, 1994: fig. 2B) and Heintzichthys (Carr, 1991: fig. 2). In these arthrodires the infraorbital sensory lines are rather short and do not run along the whole suborbital plates as in camuropiscids. A continuation of the suborbital branch of the infraorbital sensory line in the rostral plate is not observed in any other arthrodire except in Carolowilhelmina.

A fragment of the submarginal plate comes possibly from the left side of the skull. The narrow oblique ridge on its visceral surface (Fig. 7e) probably bounds the 


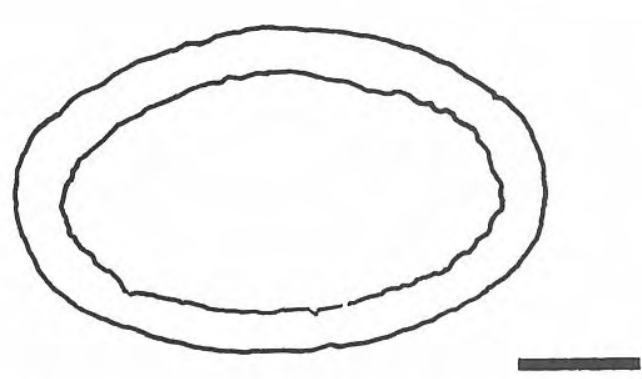

Figure 13. Carolowilhelmina geognostica Carls, 1995. Rostral plate, oblique cross section of the anterior end. Scale bar $=1 \mathrm{~cm}$.

depression for the hyomandibula (Lelièvre, 1984: fig. 12A; Carr, 1991: fig. 5C).

In Holonema and several other arthrodires (e.g., Hadrosteus, Leiosteus, Belosteus) the eye opening is usually circular and the sclerotic ring consists of four plates (Stensiö, 1963: pls. 22, 23, 25, 26, 42; Miles, 1971). More rarely the ring includes five plates as, e.g., in Goodradigbeeon (White, 1978). The fifth plate does not reach the eye opening as observed also in the acanthothoracid Murrindalaspis (Long and Young, 1988: figs. 1-3A). The plates of the dermal sclerotic ring of Murrindalaspis are considerably more ornamented than those of Carolowilhelmina (Fig. 16). The larger anterior plate (Scl.1), the dorsal plate (Scl.2), and the smaller ventral plate (Scl.4) of Carolowilhelmina could correspond to the scl.1, scl.5 and scl.4 plates of Murrindalaspis, and the posterior plate (Scl.3) to the scl.3 and scl. 2 plates of Murrindalaspis, respectively. If such a correlation of the plates is valid, then an orientation of the sclerotic ring in the orbital opening with a more or less horizontal position of the long axis of the eye opening of Carolowilhelmina can be considered plausible (Fig. 11). In Holonema the sclerotic plates are thick and meet in butt joints (Miles, 1971: figs. 37-39). In Carolowilhelmina the thin plates show overlap areas and contact faces as are known, e.g., in the sclerotic plates of Gymnotrachelus (Carr, 1994) and Torosteus (Gardiner and Miles, 1990: fig. 28). There is also resemblance in the ornamentation of the rings in these arthrodires: tubercles are densest medially. However, in Carolowilhelmina the tuberculated ornamentation occupies a smaller part of the sclerotic plates than in Gymnotrachelus. The orbital opening of Carolowilhelmina is ovoid, as is the opening in Heintzichthys. In both arthrodires the sclerotic plates are finely grooved laterally (Carr, 1995: fig. 16A). Bullerichthys (Dennis and Miles, 1980: fig. 7) has also medially tuberculated and laterally grooved sclerotic plates, but their outer edges are denticulated. In Carolowilhelmina the plates are of equal width. Tubonasus has a sclerotic plate with one end much wider than the other (Dennis and Miles, 1979b: fig. 17A). Oxyosteus shows a structure of the eye region different from that of Carolowilhelmina. Small circular sclerotic rings are situated in the central part of the oval orbital openings (Gross, 1932: fig. 18A,B; Stensiö, 1963: pl. 54).

In dorsal view the configuration of the inferognathal

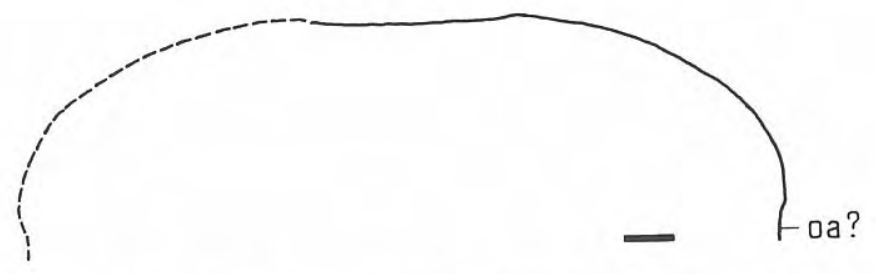

Figure 14. Carolowilhelmina geognostica Carls, 1995. Cross section of the skull-roof approximately at the level of the ossification centres of the postorbital plates. Scale bar $=1 \mathrm{~cm}$.

plate of Carolowilhelmina resembles that of the inferognathal of Homostius (Mark-Kurik, 1992), the plate being anteriorly concave and posteriorly convex, but the anterior portion of the plate is not twisted as in Homostius. The anterior concavity of the inferognathal plate is observed also in Brachyosteus (Stensiö, 1963: fig. $120 \mathrm{G})$. The inferognathals of both Carolowilhelmina and Homostius completely lack teeth, and there are grooves running along the labial surface of the blade. Ventrally from the groove (Fig. 17: gr.Mm) the labial surface has been in contact with the mentomeckelian bone. The spongy knob-like structure in Carolowilhelmina (Fig. 17) is not comparable with the teeth in other placoderms. The biting surface of the inferognathal in Rolfosteus is worn but shows some tiny teeth. In Tubonasus the plate possesses shearing edges (Dennis and Miles, 1979b). The blade in the inferognathal of Carolowilhelmina is shallower than those of Rolfosteus and Tubonasus, and particularly of Oxyosteus. In the latter the biting division possessed a sloping, comparatively wide functional edge, which could have been used for crushing (Gross, 1967: fig. $2 \mathrm{H}$ ). It appears that all the above-mentioned longsnouted arthrodires had different feeding habits.

Among numerous placoderm parasphenoids discussed by Dennis-Bryan (1995) only few have as simple a structure as that of Carolowilhelmina. In its long and narrow shape the bone resembles the parasphenoid of Trematosteus (Stensiö, 1963: fig. 92A) but lacks grooves and foramina known in Trematosteus. A ventral median crest (Fig. 18: cr.m) in the pre-hypophysial part of the parasphenoid of Carolowilhelmina is comparable to that in an undeterminable pachyosteomorph (Stensiö, 1963: fig. $115 \mathrm{~A}$ ). The ventral surface of the posterior portion of the bone of Carolowilhelmina shows some similarity with the shorter and wider leaf-like parasphenoid of Gymnotrachelus (Carr, 1994: fig. 9B). Long-snouted Tubonasus has a much shorter, deeper, and more complicated parasphenoid (Long, 1988b: figs. 1B-D, 3). In Rolfosteus the parasphenoid has not been discovered (Dennis and Miles, 1979b).

According to Lelièvre (1995), Maideria is fairly distant from the camuropiscids, which form a closely related group. The brachydeiroids, also considered as a common group, have no relationships with the camuropiscids (Gardiner and Miles, 1994).

Carolowilhelmina seems to be closer to the camuropiscids rather than to the brachydeiroids, as the latter, with rare exceptions, have comparatively simple 

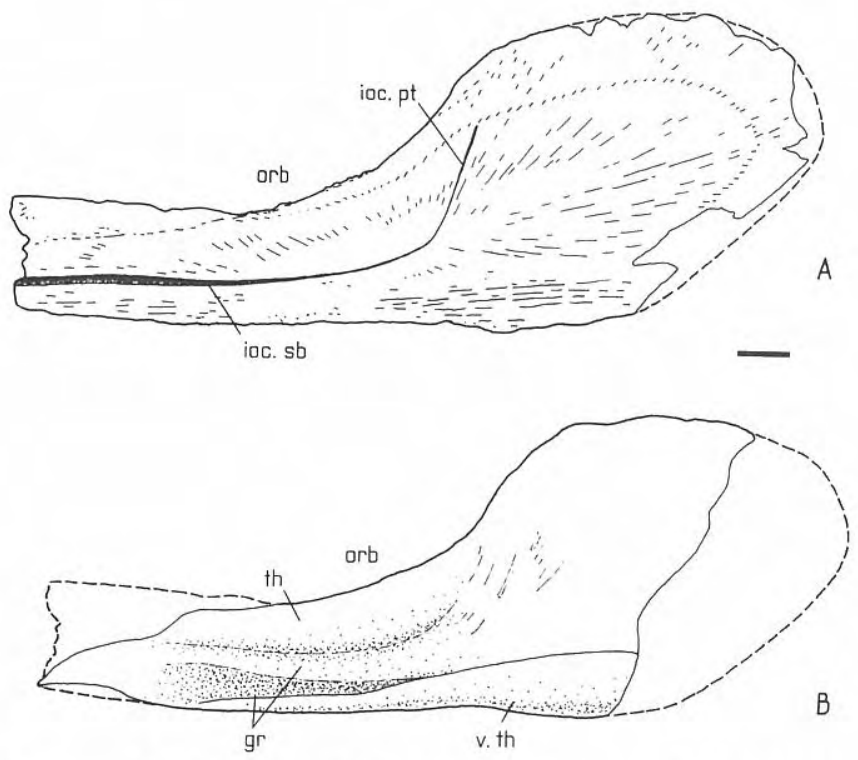

Figure 15. Carolowilhelmina geognostica Carls, 1995. Suborbital plates. A. Left suborbital plate, external view. B. Right suborbital plate, visceral view. Scale bar $=1 \mathrm{~cm}$.

outlines of the skull-roof plates (Denison, 1978: figs. 55, 56). In brachydeiroids the cheek plates are rigidly sutured to the skull-roof. Their suborbital plate articulates with the preorbital plate, but in camuropiscids with the postnasal plate (Dennis and Miles, 1979a, b; Long, $1988 \mathrm{a}, \mathrm{b})$. Carolowilhelmina shows neither of these characters.

In camuropiscids and Oxyosteus (Gross, 1932) the preorbital plates meet at the midline unlike in Carolowilhelmina and Kendrickichthys (Dennis and Miles, 1980), where the preorbital plates are separated by the rostral and pineal plates (in Kendrickichthys also by the postpineal plate). In Carolowilhelmina the rostral plate has an extremely long posteromedian lobe.

Carolowilhelmina reveals characters that do not coincide with those of either Maideria, camuropiscids or brachydeiroids. Such characters as lateral spines of the rostral plate, the supraorbital and central sensory lines meeting their antimeres at the midline of the skull, the suborbital branches of the infraorbital sensory lines probably running along the ventral surface of the rostral plate, almost straight and low toothless inferognathals, and a small flat and simple parasphenoid are unique and distinguish the new genus from all known arthrodires.

\section{PALAEOGEOGRAPHICAL AND PALAEOECOLOGICAL REMARIS}

The stratigraphical horizon of Carolowilhelmina geognostica, that is the pumilio bed below the dark shales of the Kacak Event, is the oldest pumilio bed known up to now, as it is in the late Eifelian kockelianus Conodont Zone, whereas the well known pumilio horizons elsewhere are within the Givetian. Probably, this bed represents the lowest accumulation rate within the 4000

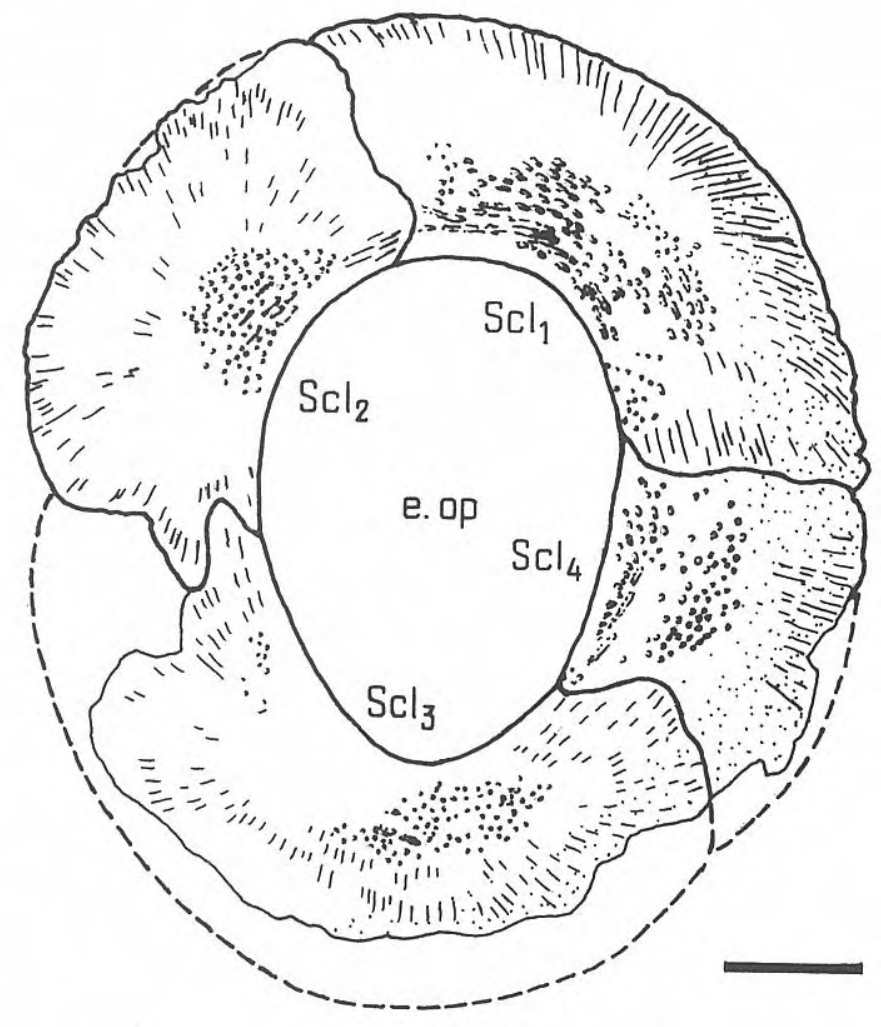

Figure 16. Carolowilhelmina geognostica Carls, 1995. Right sclerotic ring. Reconstruction based mainly on the plates of the right ring, dorsal plate $\left(\mathrm{Scl}_{2}\right)$ after the unit in left ring. Scale bar $=1 \mathrm{~cm}$.

$m$ of Devonian sediments in Celtiberia. At the same time, it also marks the start of a phase of accelerated deepening of the sea, during which benthos disappeared and only plankton (dacryoconarids), epiplankton (bivalves like Buchiola and "Posidonia", the small brachiopod "Terebratula" pumilio and some tiny chonetacean taxa), and nekton (ammonoids and orthoconic cephalopods) constituted the invertebrate fauna. The abundance of epiplankton must have been attached to floats of algae, which may also have contributed to the abundance of organic matter preserved in the anoxic sediment. Besides Carolowilhelmina, the crossopterygian Grossius stems from this bed, and a few still unidentified medium-sized bones have been found in calcareous nodules of similar facies just above the base of the following Recutanda Formation.

The deepening of the Celtiberian sea had progressed since the costatus Conodont Zone. This tendency can also be observed in other parts of the Ibero-Armorican Trough, which was an intra-cratonic basin, but probably had access to the open Palaeotethys east of Celtiberia. During the deposition of the pumilio bed, siliciclastic influx was extremely reduced, but it returned soon after the beginning of the Givetian, when barren distal turbiditic siltstones and fine-grained sandstones were formed that alternate with black shales. After accumulation of about $125 \mathrm{~m}$ of sediment already during the earliest Givetian, the depth of the sea in Celtiberia 


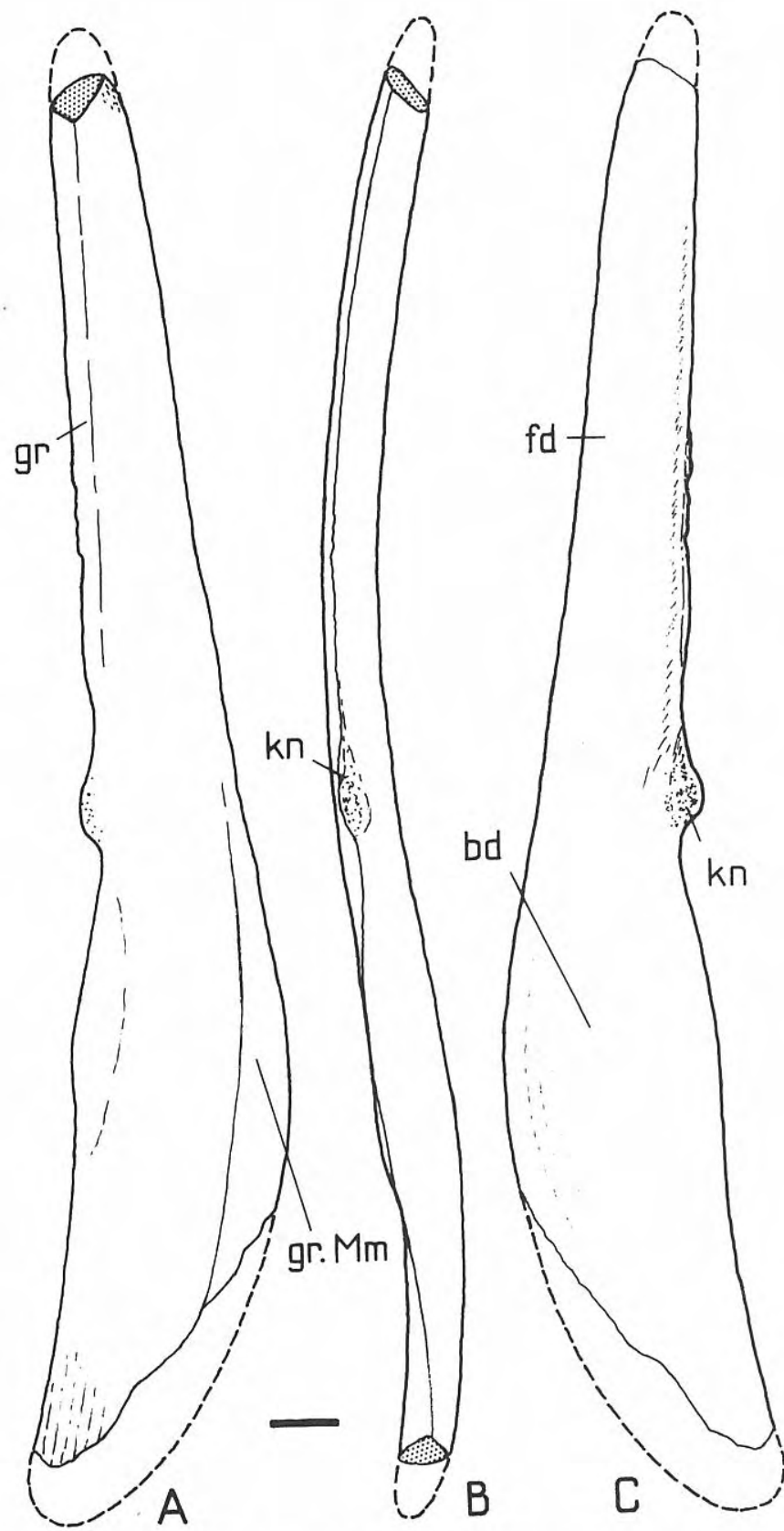

Figure 17. Carolowilhelmina geognostica Carls, 1995. Right inferognathal plate. A. Labial view. B. Dorsal view. C. Lingual view. Anterior end reconstructed after the left inferognathal plate. Scale bar $=1 \mathrm{~cm}$.

returned to shallow neritic conditions with deposition of thick alternations of sandstones and shales (Carls, 1988). This suggests a water-depth of hardly $200 \mathrm{~m}$ for the basin, in which Carolowilhelmina geognostica was fossilized just before the Kacak Event. Having been embedded on the anoxic bottom of the basin, it was not affected by incrusting or boring invertebrates. The fish must have lived near the surface. The presence of algal floats, as inferred from the abundance of epiplankton, suggests that this large arthrodire with its elongated head and large eyes was a speed-swimming predator hunting

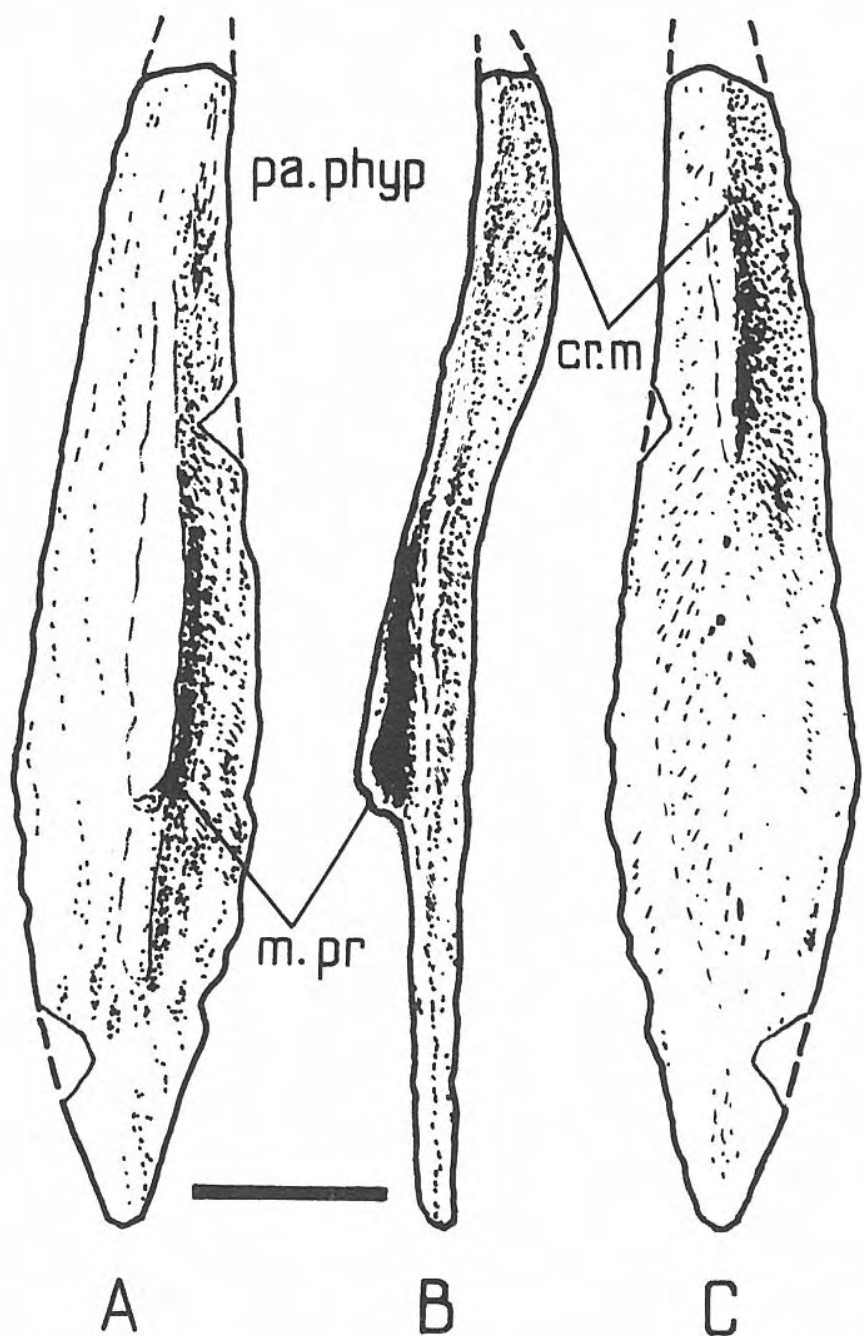

Figure 18. Carolowilhelmina geognostica Carls, 1995. Parasphenoid. A. Dorsal view. B. Right lateral view. C. Ventral view. Same as Fig. 4d-f. Scale bar $=1 \mathrm{~cm}$.

under the algal floats. Its immigration from the nearby oceanic Palaeotethys is possible.

\section{ACKNOWLEDGEMENTS}

The preparation of the skull could only be ventured in connection with the grant Ca $43 / 15-2$ of the Deutsche Forschungsgemeinschaft for a wider scope of studies of Devonian fish remains from Spain. In the Institut für Geowissenschaften, Braunschweig, we thank Andrea van der Veen for her active help with photography and Falk Lehnhoff for his support with text processing. Klaus Himstedt of the Faculty workshop, Braunschweig, built the stative that supports the fossil. Many specialists of paleoichthyology have encouraged P. C. during the preparation and have furnished valuable advice. An outstanding contribution was that one by Hans-Peter Schultze, Göttingen-Lawrence-Berlin: In 1993, he recollected that bone fragments that had been found already in 1971 and were then examined by him, are the anterior 
portion of the rostrum as here presented. E. M.-K. thanks the Estonian Science Foundation (Grant 3499) for financial support and Hervé Lelièvre, Muséum national d'Histoire naturelle, Paris, for useful discussion. Our sincere thanks go to Alain Blieck, Lille, and José Ignacio Valenzuela-Ríos, Valencia, for reviewing and improving this work.

\section{REFERENCES}

Carls, P. 1988. The Devonian of Celtiberia (Spain) and Devonian paleogeography of SW Europe. In: Devonian of the world (Proceedings of the $2^{\text {nd }}$ International Symposium on the Devonian System, Calgary 1987) (Eds. N. J. McMillan, A. F. Embry and D. J. Glass). Canadian Society of Petroleum Geologists Memoir, 14 (1), 421-466.

Carls, P. 1995. Carolowilhelmina geognostica - ein Meisterwerk der Evolution. Carolo-Wilhelmina, Mitteilungen, Technische Universität Braunschweig, Jahrgang 30, Heft II, 18-25.

Carr, R.K. 1991. Reanalysis of Heintzichthys gouldii (Newberry), an aspinothoracid arthrodire (Placodermi) from the Famennian of northern Ohio, with a review of brachythoracid systematics. Zoological Journal of the Linnean Society, 103, 349-390.

Carr, R.K. 1994. A redescription of Gymnotrachelus (Placodermi: Arthrodira) from the Cleveland Shale (Famennian) of Northern Ohio, U.S.A. Kirtlandia, 48, 321.

Carr, R.K. 1995. Placoderm diversity and evolution. Bulletin du Muséum national d'Histoire naturelle, Paris, $4^{\mathrm{e}}$ série, 17, Section C, (1-4), 85-125.

Denison, R.H. 1978. Handbook of Paleoichthyology. 2. Placodermi. Gustav Fischer Verlag, Stuttgart, 128 pp.

Dennis, K. and Miles, R.S. 1979a. A second eubrachythoracid arthrodire from Gogo, Western Australia. Zoological Journal of the Linnean Society, 67, 1-29.

Dennis, K. and Miles, R.S. 1979b. Eubrachythoracid arthrodires with tubular rostral plates from Gogo, Western Australia. Zoological Journal of the Linnean Society, 67, 297-328.

Dennis, K. and Miles, R.S. 1980. New durophagous arthrodires from Gogo, Western Australia. Zoological Journal of the Linnean Society, 69, 43-85.

Dennis, K. and Miles, R.S. 1981. A pachyosteomorph arthrodire from Gogo, Western Australia. Zoological Journal of the Linnean Society, 73, 213-258.

Dennis-Bryan, K. 1987. A new species of eastmanosteid arthrodire (Pisces: Placodermi) from Gogo, Western Australia. Zoological Journal of the Linnean Society, 90, $1-64$.

Dennis-Bryan, K. 1995. Some comments on the Placoderm parasphenoid. Bulletin du Muséum national d'Histoire naturelle, Paris, $4^{\mathrm{e}}$ série, 17, Section C, (1-4), 127-142.

Gardiner, B.G. and Miles, R.S. 1990. A new genus of eubrachythoracid arthrodire from Gogo, Western Australia. Zoological Journal of the Linnean Society, 99, 159-204.
Gardiner, B.G. and Miles, R.S. 1994. Eubrachythoracid arthrodires from Gogo, Western Australia. Zoological Journal of the Linnean Society, 112, 443-477.

Gross, W. 1932. Die Arthrodira Wildungens. Geologische und Palaeontologische Abhandlungen, Neue Folge, 19. Heft 1, 1-61.

Gross, W. 1967. Über das Gebiss der Acanthodier und Placodermen. Journal of the Linnean Society (Zoology), 47, 121-130.

Lelièvre, H. 1984. Antineosteus lehmani n.g., n.sp., nouveau Brachythoraci du Dévonien inférieur du Maroc présaharien. Annales de Paléontologie, 70, 115-158.

Lelièvre, H. 1995. Description of Maideria falipoui n.g., n.sp., a long snouted brachythoracid (Vertebrata, Placodermi, Arthrodira) from the Givetian of Maider (South Morocco), with a phylogenetic analysis of primitive brachythoracids. Bulletin du Muséum national d'Histoire naturelle, Paris, $4^{\mathrm{e}}$ série, 17, Section C, (1-4), 163-207.

Long, J.A. 1988a. A new camuropiscid arthrodire (Pisces: Placodermi) from Gogo, Western Australia. Zoological Journal of the Linnean Society, 94, 233-258.

Long, J.A. 1988b. New information on the Late Devonian arthrodire Tubonasus from Gogo, Western Australia. Memoir of the Association of Australasian Palaeontologists, 7, 81-85.

Long, J.A. 1994. A second incisoscutid arthrodire (Pisces, Placodermi) from the Late Devonian Gogo Formation, Western Australia. Alcheringa, 18, 59-69.

Long, J.A. and Young, G.C. 1988. Acanthothoracid remains from the Early Devonian of New South Wales, including a complete sclerotic capsule and pelvic girdle. Memoir of the Association of Australasian Palaeontologists, 7, 1231.

Mark-Kurik, E. 1992. The inferognathal in the Middle Devonian arthrodire Homostius. Lethaia, 25, 173-178.

Mark-Kurik, E. and Carls, P. 1999. Long-snouted arthrodires (Placodermi). In: Major Events in Early Vertebrate Evolution: Palaeontology, Phylogeny and Development. A joint Systematics Association/Natural History Museum meeting, 8-9 April 1999, Abstracts, 48-49.

Miles, R.S. 1971. The Holonematidae (placoderm fishes), a review based on new specimens of Holonema from the Upper Devonian of Western Australia. Philosophical Transactions of the Royal Society of London. B, 263 (849), 101-234.

Miles, R.S. and Dennis, K. 1979. A primitive eubrachythoracid arthrodire from Gogo, Western Australia. Zoological Journal of the Linnean Society, 66, 31-62.

Miles, R.S. and Westoll, T.S. 1968. The placoderm fish Coccosteus cuspidatus Miller ex Agassiz from the Middle Old Red Sandstone of Scotland. Part I. Descriptive morphology. Transactions of the Royal Society of Edinburgh, 67, 373-476.

Schultze, H.-P. 1973. Crossopterygier mit heterozerker Schwanzflosse aus dem Oberdevon Kanadas, nebst einer Beschreibung von Onychodontida-Resten aus dem Mitteldevon Spaniens und aus dem Karbon der USA. Palaeontographica, 143, Abt. A, 188-208. 
Stensiö, E. 1963. Anatomical studies on the arthrodiran head. Part I. Kungliga Svenska Vetenskapsakademiens Handlingar, 4. serien, 9 (2), 1-419.

Wang, Junqing and Wang, Nianzhong 1983. A new genus of Coccosteidae. Vertebrata PalAsiatica, 21, 1-8.

Wang, Ronghu 1987. Das Eifelium bei Loscos und Monforte in der Cordillera Ibérica Oriental-Kartierung, Gliederung, Stratigraphie und Conodontenfauna.
Diploma-Thesis, Technische Universität Braunschweig. 209 pp. [Unpublished].

Wang, Ronghu 1991. Conodonten-Biofazies und Biostratigraphie der Moyuela-Formation (Eifelium) in Keltiberien, Spanien. Neues Jahrbuch für Geologie und Paläontologie, Monatshefte, 1991, 177-189.

White, E.I. 1978. The large arthrodiran fishes from the area of the Burrinjuck Dam, N.S.W. Transactions of the Zoological Society of London, 34, 149-262.

Manuscrito recibido: 24 de julio, 2001 Manuscrito aceptado: 22 de noviembre, 2001 